\title{
Keeping an Insecure Career under Control: The Longitudinal Interplay of Career Insecurity, Self-Management, and Self-Efficacy
}

\author{
Aida Alisic \& Bettina S. Wiese \\ Institute of Psychology, RWTH Aachen University, Germany
}

Note: This is a pre-print version of an in-press, accepted manuscript. Please cite as:

Alisic, A., \& Wiese, B. S. (2020, In press). Keeping an insecure career under control: The longitudinal interplay of career insecurity, self-management, and self-efficacy. Journal of Vocational Behavior.

\section{Author Note}

Correspondence concerning this manuscript should be addressed to Aida Alisic, RWTH Aachen University, Institute of Psychology, Jaegerstrasse 17-19, 52056 Aachen, Germany, Email: Alisic@psych.rwth-aachen.de 


\begin{abstract}
Career insecurity is a central topic in career research because many career paths are characterized by high levels of uncertainty. In academia, individuals face not only high levels of insecurity in the early career phase but also the responsibility of managing their careers by themselves. Building on the motivational theory of life-span development and the social cognitive theory of self-regulation, this longitudinal study investigates the relationship between perceived career insecurity, work-related self-management, and occupational selfefficacy beliefs based on a sample of 3,118 PhD students and PhD holders. We employed the random intercept cross-lagged panel model (RI-CLPM) to separate between-person effects from within-person effects across eight measurement points (6-month time intervals). At the between-person level, career insecurity was negatively correlated with self-management and self-efficacy. At the within-person level, (a) increases in self-management and self-efficacy predicted decreases in subsequent career insecurity, and (b) increases in career insecurity predicted decreases in subsequent self-management and self-efficacy. Mediation analyses showed self-management to reduce career insecurity via increases in self-efficacy.
\end{abstract}

Keywords: self-management, self-efficacy, career insecurity, academic career, random intercept cross-lagged panel model (RI-CLPM)

Highlights:

- Eight-wave longitudinal study with 3,118 young scientists

- Self-management, self-efficacy, and career insecurity relate at the within level.

- Increases in self-management/self-efficacy predict decreases in career insecurity.

- Increases in career insecurity predict decreases in self-management/self-efficacy.

- Self-management reduces career insecurity via increases in self-efficacy. 
Keeping an Insecure Career under Control: The Longitudinal Interplay of Career Insecurity, Self-Management, and Self-Efficacy

\section{Introduction}

Academic careers can be considered to be a prototype of protean and boundaryless careers (e.g., Baruch \& Hall, 2004; Ortlieb \& Weiss, 2018). The academic career environment is characterized by high levels of uncertainty (e.g., Ortlieb \& Weiss, 2018). Many young scientists have non-permanent positions, and those who aim to obtain a tenured professorship struggle with high levels of competitiveness (Harley, Muller-Camen, \& Collin, 2004). With respect to the consequence of uncertainty, it has repeatedly been shown that young scientists' career insecurity is associated with high work stress and turnover intentions (Dorenkamp \& Weiß, 2017; Kinman \& Jones, 2008).

There is a growing interest in factors that reduce perceived career insecurity (Ortlieb \& Weiss, 2018; Spurk, Kauffeld, Meinecke, \& Ebner, 2016). From theoretical perspectives of developmental regulation (Heckhausen, Wrosch, \& Schulz, 2010) and self-regulation (Bandura, 1986, 1991, 1997), we suggest self-management strategies and self-efficacy beliefs to represent particularly promising candidates. In fact, in the context of protean and boundaryless careers, as well as with regard to the anticipated changes emerging from the digitization and automation of work (also known as the fourth industrial revolution; Schwab, 2016), career self-management has been proposed as a coping mechanism suitable for handling career uncertainty and change (e.g., Briscoe, Henagan, Burton, \& Murphy, 2012; Hall \& Mirvis, 1996; Wilhelm \& Hirschi, 2019). Similarly, self-efficacy is considered an important resource for coping with the unpredictability of today's work and career environment (e.g., Garcia, Restubog, Bordia, Bordia, \& Roxas, 2015; Hirschi, Lee, Porfeli, \& Vondracek, 2013). Thus, engaging in career self-management behavior and fostering selfefficacy beliefs should reduce perceived career insecurity. However, as information about these associations is not available in the literature, investigating them represents an important 
research gap to be closed by our study. Furthermore, the present study also takes into consideration the possibility that both self-management and self-efficacy beliefs might be negatively affected when facing an increase in career insecurity.

Determining whether a reciprocal relationship between self-management/self-efficacy and career insecurity exists is of practical relevance. It can indicate a potential feedback loop or spiral that could impact an individual's career trajectory. In the case of a gain spiral, gains in self-management behaviors and self-efficacy beliefs could lead to lower career insecurity, which in turn could have a reinforcing impact on further self-management and self-efficacy. In contrast, in the case of a loss spiral, career insecurity might have a detrimental effect on work-related self-management and occupational self-efficacy; this in turn could lead to even higher career insecurity. This is particularly important for young academics confronted with high insecurity, since self-management and self-efficacy are regarded as malleable and have been repeatedly identified as trainable competencies (Bandura, 1986; Kossek, Roberts, Fisher, \& Demarr, 1998; Schmitz \& Wiese, 2006). Thus, they represent changeable resources young academics can make use of and build up rather than feeling powerless when faced with career insecurity.

Based on the notion of triadic reciprocity, which states that personal, behavioral, and environmental factors impact one another bidirectionally, Social Cognitive Theory (SCT; Bandura, 1986, 1991, 1997) proposes that self-efficacy is an important predictor and consequence of self-management strategies. Thus in the present research we investigate whether self-efficacy, beyond the direct reciprocal relationships, acts a mediator in the developmental associations between career self-management and career insecurity.

Our research contributes to the literature in multiple ways. First, by being the first to examine the reciprocal interdependency of career insecurity, career self-management, and occupational self-efficacy, we provide a test to a central reciprocity assumption (triadic reciprocity) of SCT. Second, by investigating occupational self-efficacy as a mediator, we 
explore a crucial explanatory mechanism in the reciprocal relationship between career selfmanagement and career insecurity. Third, we contribute to the understanding of career selfmanagement by considering career insecurity as its antecedent. In other words, we suggest that self-management and self-efficacy are not only important factors for coping with career insecurity but also vulnerable resources. Fourth, and most importantly, we advance our understanding of the dynamic interplay between career insecurity, career self-management and occupational self-efficacy by applying a longitudinal study design and research model that disentangles causal directions as well as between- and within-person effects.

Conceptually as well as methodologically, we enhance the career insecurity literature by using a cross-lagged longitudinal design (comprising a period of approximately four years with eight repeated measurement occasions), which allows investigation of all potential relationships between the three constructs.

From a data modeling view, considering these relationships includes being the first to build on newly developed methods in the field of cross-lagged modeling, namely the randomintercept cross-lagged panel model (RI-CLPM, Hamaker, Kuiper, \& Grasman, 2015). By employing this model, we specifically examine within-subject relationships while controlling for between-person effects and thereby explore intra-personal changes over time. Past studies in the career literature did not use methods to differentiate within-person from betweenperson effects, reporting solely on differences between individuals (e.g., individuals with high career competencies experience lower levels of insecurity; Colakoglu, 2011) without addressing how the investigated constructs develop over time within one person. Withinperson effects represent fluctuations in the level of a variable for an individual over time, whereas between-person effects refer to stable, trait-like differences between individuals (Hamaker et al., 2015). Thus, while between-person effects provide certain information, they do not inform the direction of causality between reciprocally related constructs. To disentangle the reciprocal relationships, within-person analyses are needed (Sitzmann \& Yeo, 
2013). It is important to understand the direction of influence in order to infer accurate theoretical and practical implications. If the theoretical assumptions describe within-person processes, statistical analyses should not be restricted to the estimation of between-person effects (Curran, Howard, Bainter, Lane, \& McGinley, 2014). Because self-regulation is a process of personal development (e.g., Sitzmann \& Ely, 2011), intra-individual changes in constructs of interest are of particular interest. Thereby, the present study investigates withinperson changes in the present study instead of focusing on comparisons between individuals.

\subsection{Career insecurity: Construct and past findings}

Perceived career insecurity denotes a subjective facet of low employability by feeling "powerless to maintain continuous employment" (Colakoglu, 2011, p. 50) and the fear of not reaching individual career goals (Höge et al., 2012). Thus, it can represent a major stressor for employees (Colakoglu, 2011). Structural sources of career insecurity in the academic work environment include short-term contracts, high competition for tenure-track positions, high performance standards, mobility requirements, and difficulties reconciling work and personal life (Ortlieb \& Weiss, 2018). In contrast to job insecurity, which refers to the fear of losing one's current job or important features of it (Mauno, Leskinen, \& Kinnunen, 2001), career insecurity is rather understudied despite its relevance (Trevor-Roberts, 2006). The few existing studies on career insecurity showed that the construct is conceptually different from but related to job insecurity (Höge et al., 2012; Spurk et al., 2016).

Colakoglu (2011) explored career insecurity within the framework of boundaryless careers. She investigated the relationship between career boundarylessness and subjective career success based on enactment and the stress perspectives. The enactment perspective (e.g., Weick, 1996) argues that a boundaryless career provides an individual with extensive autonomy and self-determination, contributing to career satisfaction. In contrast, the stress perspective (e.g., Mirvis \& Hall, 1996) simultaneously claims that the career insecurity resulting from pursuing a boundaryless career reduces an individual's career satisfaction. 
In line with the enactment perspective, Colakoglu (2011) found career competencies (knowing-why, knowing how, and knowing-whom) to be positively related to career autonomy and negatively to career insecurity. Consistent with the stress perspective, however, she also found support for the negative relationship of career insecurity and career satisfaction. Spurk et al. (2016) revealed career adaptability to be negatively related to career and job insecurity via perceptions of internal and external marketability. Ortlieb and Weiss (2018) examined predictors of academic career insecurity and reported the willingness to be geographically mobile, self-attribution of past success, high time investments in research, and an advanced career stage to be negatively correlated to early-career researchers' career insecurity.

\subsection{Applying developmental and self-regulation approaches to dealing with career insecurity}

In the present paper, we build on two theoretical frameworks to extend and complement the existing stream of research on career insecurity: the motivational theory of life span development (Heckhausen et al., 2010) and the social cognitive theory of selfregulation (Bandura, 1997). These theories provide the foundation for better understanding how career insecurity, work-related self-management, and occupational self-efficacy are interrelated in academic career contexts.

In their motivational theory of life span development (MTD), Heckhausen et al. (2010) propose that individuals actively influence their development by selecting and pursuing developmental goals (including career-related goals). These efforts simultaneously represent means to gain control over one's own development. Based on the Rubicon model of action phases (Gollwitzer, 1990; Gollwitzer, 2012; Heckhausen \& Gollwitzer, 1987), MTD assumes a "sequential structure of goal-oriented action cycles involving phases of goal selection, goal engagement, and disengagement in developmental regulation" (Heckhausen et al., 2010, p. 33). MTD highlights the importance of self-management strategies (in terms of goal setting and especially goal striving) in dealing with developmental demands. The theory focuses on 
control or coping strategies that are helpful for the achievement of long-term developmental goals and thereby simultaneously considers constraints (and opportunities) that could hinder (or facilitate) goal fulfillment (i.e., uncertainty of long-term careers, chronic illness, promotions, e.g., Heckhausen, 2010; Heckhausen et al., 2010). Particularly, three types of control strategies are thought to reflect goal engagement (Heckhausen et al., 2010). Selective primary control refers to the investment of behavioral resources, such as effort, time, and ability during goal pursuit. Compensatory primary control comprises the use of external resources, such as accessing assistance. Selective secondary control involves cognitive strategies, such as devaluating other competing goals. Individuals primarily strive for primary control and prefer goal engagement, especially when there are opportunities to attain their goals (Heckhausen, 2010). In the present research, we focus on behavioral goal engagement that comprises primary control, which helps an individual to stay committed to long-term goals while faced with distractions or emerging difficulties. Although MTD distinguishes between goal engagement (e.g., investing time and effort and overcoming obstacles in the pursuit of goals) and goal disengagement (e.g., distancing from unattainable goals by devaluing the goal) strategies, achieving career-related developmental goals clearly requires persistent engagement (Lechner, Tomasik, \& Silbereisen., 2016). Building on MTD, we conceptualize academic career insecurity as a central developmental demand for young scientists that can be mastered through the effective use of self-management strategies aimed at enhancing control over one's own career (Heckhausen et al., 2010). As a consequence, an increase in a young scientist's self-management capacity (i.e., primary control capacity) can be expected to result in stronger beliefs in own capacity to deal with developmental demands (i.e., self-efficacy beliefs) as well as lower levels of perceived career insecurity.

For Bandura (1991), repeated cycles of goal setting (i.e., selecting goals and forming plans on how to attain them) and goal pursuit (i.e., engaging in action strategies to accomplish a certain goal) represent central components of human adaptive agency, that is, the ability to 
increase control over one's life. Goals are defined as representations of future states for which people strive, and they mark the essential connection from cognitive processes to active behavioral change. Bandura (1991) assumes that successful engagement in goal-directed behavior strengthens self-efficacy beliefs, which in turn affect the selection and pursuit of future goals. Encompassing goal selection and goal pursuit strategies, career self-management can also be understood with regard to Bandura's social cognitive theory (SCT; Bandura, 1986, 1997). Central to the SCT is the notion of triadic reciprocal causation, which states that personal, behavioral, and environmental factors impact each other in bidirectional ways. Personal factors include internal capabilities like cognitive, emotional and physical resources. Behavioral factors relate to decisions and actions that are performed by the person. Lastly, environmental factors comprise all external resources and surrounding conditions. The theory further states that the reciprocity is based on feedback loops between the three characteristics. And these effects are assumed to unfold over time (Bandura, 1997; Goller, 2017). In addition, the theory assumes that reciprocal relations between different personal factors are present within the model (Pajares, 1997). Following the central assumption of bidirectional relationships, career insecurity would not only be influenced by, but also have an impact on career self-management.

A further important construct that should be considered when investigating the relationship between career self-management and career insecurity is self-efficacy (Bandura, 1997). Based on the framework of triadic reciprocity, SCT proposes that self-efficacy is an important predictor (internal personal factor) and consequence of self-management strategies (behavioral factor). Within the framework of triadic reciprocity of SCT, career insecurity represents - just like self-efficacy - an internal personal factor. Bandura $(1991,1997)$ assumed that self-doubt works antagonistic to self-efficacy. Career insecurity describes a doubt regarding the fulfillment of career goals. Whereas self-efficacy is assumed to motivate engagement in self-management behavior, doubts should decrease the likelihood of self- 
management. In other words, career insecurity might hinder processes related to selfmanagement.

\subsection{Conceptualizing work-related self-management}

Self-management denotes processes of goal setting and pursuit. It is important for everyday work-related behavior as well as for career development (Abele \& Wiese, 2008). Considering everyday work-related behavior, self-management is especially required in highly autonomous work settings (e.g., Bredehöft, Dettmers, Hoppe, \& Janneck, 2015). Likewise, career autonomy associated with a boundaryless career enables individuals to exercise self-management (Weick, 1996). Many scholars highlight the importance of self-set goals in contemporary careers (e.g., Hall, 2002). Yet, self-management is also important for assigned goals especially if employees are simultaneously offered high autonomy to decide how to achieve these goals (Lord, Diefendorff, Schmidt, \& Hall, 2010). Specifically, academic work is characterized by high autonomy, which in turn requires high levels of selfmanagement. In summary, young researchers need self-management capacities not only to successfully deal with everyday work demands but also to pursue their academic careers.

Career self-management as a domain-specific form of self-management (i.e., setting and pursuing career-related goals) is especially important for individual career development as it constitutes a means of enhancing perceived control over the career (King, 2004).

Because academic work and career environment are characterized by high levels of autonomy and uncertainty, self-management strategies are essential for successfully manage everyday work tasks (e.g., running experiments, writing research papers, etc.) as well as sustaining an academic career.

\subsection{Conceptualizing occupational self-efficacy}

Self-efficacy describes an individual's belief in being able to successfully pursue goals and to deal with difficulties one might face in the goal-pursuit process (Bandura, 1986, 1997). It is an internal cognitive resource of enormous importance for the entire self-regulation 
process. Agents with higher self-efficacy select more difficult goals to pursue and persist longer in the case of obstacles (Bandura, 1986, 1997). In fact, beliefs about the individual's capacities to successfully engage in goal-directed behavior are seen as a better predictor of this particular behavior than actual capacities (Bandura, 1986). Further research showed selfefficacy to be negatively associated with procrastination (Steel, 2007; Wäschle, Allgaier, Lachner, Fink, \& Nückles, 2014).

Self-efficacy can be subdivided into generalized or more domain-specific self-efficacy beliefs. In the present study, we use occupational self-efficacy, which explicitly refers to the work domain (Rigotti, Schyns, \& Mohr, 2008).

\subsection{Linking career insecurity to work-related self-management and occupational self-efficacy}

Perceived career insecurity interferes with career-related goals and represents a potential threat to young scientists' career development. Thus, successfully coping with or controlling career insecurity represents a central developmental demand at an early career stage. Heckhausen (2010) argues that when confronted with uncertainty of long-term careers, individuals with efficient goal engagement strategies (in addition to other personal resources like educational qualification) are more likely to achieve their work-related goals "particularly when opportunities for upward mobility are institutionalized in the educational or career system" (Heckhausen, 2010, p. 156). Similarly, research on coping with occupational uncertainty due to changes in labor market and working conditions (e.g., difficulties in career planning, risk of getting unemployed) showed goal engagement in response to this uncertainty (e.g., investing time and effort in goal pursuit) to be associated with higher levels of subjective well-being and objective success factors (e.g., Grümer, Silbereisen, \& Heckhausen, 2013; Körner, Lechner, Pavlova, \& Silbereisen, 2015). In summary, career self-management strategies may represent a developmentally appropriate response to career insecurity.

As outlined above, SCT (Bandura, 1986, 1997) provides a theoretical reasoning for a reciprocal relationship between self-efficacy, self-management and career insecurity. The core 
of SCT is the notion of triadic reciprocal causation, which states that person, behavior, and environment impact each other in a bidirectional way. Applied to our study, self-management strategies of goal pursuit represent the behavioral component, whereas self-efficacy and career insecurity apply to internal personal factors. Please note that our research did not include explicit environmental factors. However, our chosen constructs reflect specificity in the nature of academic careers. Particularly career insecurity is strongly influenced by environmental factors such as contract type and job prospects (Höge et al., 2012) and encompasses the perception of environmental factors. Based on the notion of triadic reciprocity, we expected work-related self-management, occupational self-efficacy, and career insecurity to be reciprocally related.

\subsubsection{Work-related self-management and occupational self-efficacy}

Within the SCT framework self-management and self-efficacy are seen as key behavioral and cognitive resources for personal development and change. Bandura (1991) assumes that successful goal-directed behavior strengthens self-efficacy beliefs, which, in turn, foster the selection and pursuit of future goals. Supporting this assumption, past research has shown that a positive dynamic relationship of self-efficacy and self-management strategies exists (Bandura, 1991). Further support is provided by studies that showed selfmanagement training to also increase self-efficacy (e.g., Frayne \& Latham, 1987). A recent longitudinal study by Wolf, Herrmann, and Brandstätter (2018) found self-efficacy at T1 to be associated with more adaptive goal striving at T2. More precisely, self-efficacy was found to reduce the development of an action crisis, that is, a conflict in which the individual is torn between goal striving and disengagement. Considering the achievement of goals, Wäschle and colleagues (2014) investigated reciprocal feedback loops between self-efficacy and perceived goal achievement in a longitudinal study with university students. Using multilevel analysis for growth curve models (which allows to control for time-invariant, between-individual confounds), they found evidence for a positive, amplifying feedback loop between both 
constructs. Building on Bandura's (1991) assumptions of the reciprocal relationships between goal achievement and self-efficacy beliefs and on the above-mentioned empirical results, we expected to find bidirectional positive relationships over time from work-related selfmanagement to occupational self-efficacy, and from occupational self-efficacy to workrelated self-management:

Hypothesisla (H1a): Work-related self-management has a positive effect on occupational self-efficacy over time.

Hypothesis1b (H1b): Occupational self-efficacy has a positive effect on work-related self-management over time.

\subsubsection{The effect of self-management and self-efficacy on career insecurity}

Considering the relationship of self-management and self-efficacy with career insecurity, we expected negative relationships. Research on job insecurity has repeatedly argued that a "lack of control" constitutes the core insecurity problem (De Witte, 2005; Greenhalgh \& Rosenblatt, 1984; Vander Elst, Van den Broeck, De Witte, \& De Cuyper, 2012). Comparable to job insecurity, career insecurity implies a lack of control or powerlessness over the achievement of individual career goals (Colakoglu, 2011; Höge et al., 2012). According to SCT, self-management constitutes a means of gaining control in one's life and career (Bandura, 1997; Skinner, 1997), while self-efficacy concerns “people's beliefs about their capabilities to exercise control over their own level of functioning” (Bandura, 1991, p. 257). Likewise, MTD views self-management strategies (in terms of choosing and pursuing goals) as means of exerting control over the environment and actively influencing one's own (vocational) development (Heckhausen, 2010).

In line with these theoretical assumptions, Ito and Brotheridge (2001) found an individual's perceived control to be important when coping with workplace stress that arises from uncertainty. Moreover, Höge et al. (2012) found young scientists who viewed themselves to be highly responsible for their own career to also report lower career insecurity 
at a given point in time. Thus, it is reasonable to assume that through increase in efficient work-related self-management and gains in occupational self-efficacy, individuals' perceptions of personal control over their vocational future increases, which, in turn, reduces feelings of career insecurity.

Hypothesis 2 (H2): Work-related self-management has a negative effect on career insecurity over time.

Hypothesis 3 (H3): Occupational self-efficacy has a negative effect on career insecurity over time.

Given that career self-management strategies constitute career-related control strivings and self-efficacy represents control beliefs, we further assumed self-efficacy would mediate the effect of self-management on career insecurity: Increasing self-management activity might strengthen an individual's belief to have more control over attaining career goals, which then may result in reduced career insecurity.

Hypothesis 4 (H4): Occupational self-efficacy partially mediates the negative effect of work-related self-management on career insecurity.

\subsubsection{The effect of career insecurity on self-management and self-efficacy}

Considering the direction of relationship, there are reasons to assume that career insecurity could also decrease self-management and self-efficacy. Bandura (1991; 1997) assumed self-doubt and self-efficacy to cause contrary effects. Hence, representing a doubt regarding the fulfillment of career goals, career insecurity should hinder effort and persistence in the goal striving processes. Accordingly, in a recent cross-sectional study with university students by Chamandy and Gaudreau (2019), career doubt was found to be negatively associated with perceived goal progress in academic and career goals as well as with taskoriented coping (e.g., persistence and goal-directed effort), while positively related to disengagement-oriented coping (e.g., withdrawal from goal-directed effort). The negative association between career doubt and both academic and career goal progress was mediated 
through reduced task-oriented coping. SCT further argues that people's beliefs about the extent to which a situation is controllable has an effect on their self-regulation abilities in that "when people believe the environment is controllable (...), they are motivated to exercise fully their personal efficacy" (Wood \& Bandura, 1989, p. 374). In this regard, the perceived threat of not reaching career goals could decrease self-efficacy beliefs and self-management capacity. Empirical support for the negative effect of career insecurity on self-efficacy is provided by recent longitudinal studies that found job insecurity to decrease general and occupational self-efficacy (Etehadi \& Karatepe, 2018; Van Hootegem \& De Witte, 2019). Correspondingly, previous research indicated that job insecurity has an inhibiting effect on career planning (e.g., Klehe, Zikic, Van Vianen, \& De Pater, 2011). Thus, we propose:

Hypothesis 5 (H5): Career insecurity has a negative effect on work-related selfmanagement over time.

Hypothesis 6 (H6): Career insecurity has a negative effect on occupational selfefficacy over time.

As above, we also considered increases in career insecurity as causing decreases in self-management via decreases in self-efficacy:

Hypothesis 7 (H7): Occupational self-efficacy partially mediates the negative effect from career insecurity to work-related self-management.

Figure 1 illustrates our hypothesized model and encompasses all potential cross-lagged relationships between the three constructs that were examined. We built our analyses on a longitudinal design. Scholars have called for longitudinal studies and "sophisticated designs to consider that the proposed sequences of relationships may in fact be reversed or reciprocal in nature, as advocated by theories of self-regulation" (Chamandy \& Gaudreau, 2019, p. 164; Colakoglu, 2011). The few studies which, inter alia, analyzed the impact of agentic constructs (e.g., career adaptability, protean career orientation) on perceived career insecurity are mainly cross-sectional (Colakoglu, 2011; Höge, Brucculeri, \& Iwanowa, 2012; Ortlieb \& Weiss, 
2018) or based on only two measurement occasions without assessing each construct at each wave (Spurk et al., 2016). Neither cross-sectional studies nor longitudinal studies neglecting autoregressive effects are able to capture long-term effects and to rule out reversed causation.

By explicitly testing reciprocal relationships, we investigated whether selfmanagement and self-efficacy affect career insecurity, whether career insecurity affects selfmanagement and self-efficacy, or whether this relationship is reciprocal. Above that, our design allowed testing longitudinal mediation effects as each construct was measured at each occasion and thus the potential predictor, mediator, and criterion was assessed at subsequent measurement points. Most importantly, by using a relatively new modeling approach that allows to examine the within-person cross-lagged correlation (RI-CLPM, Hamaker et al., 2015), the present study tests whether changes in an individual's level of self-management, self-efficacy, and career insecurity will lead to further changes in one of these measures. This novel approach allows drawing more accurate conclusions about the nature of longitudinal relationships.

\section{Method}

\subsection{Procedure and participants}

The study was part of a larger nine-wave research project on the career paths of young scientists that began in 2014. Participants were recruited via Internet platforms, mailing lists, human resource departments of universities and large companies. We analyzed questionnaire data (online surveys) from a sample of academic researchers from different STEM fields: (6.7\% mathematics, $9.3 \%$ computer science, $38.7 \%$ engineering sciences, $45.3 \%$ natural sciences). Participants mostly lived in different countries, but the majority lived in Germany (93.8\%). The remaining respondents lived in other European countries (4.1\%), the Americas (1.3\%), Australia (0.3\%), and Asia (0.3\%; 0.2\% n.a.). Correspondingly, the majority held German citizenship (90.6\%). 
The current study used eight of the nine measurement points, with approximately 6month intervals, henceforth referred to as $\mathrm{T} 1-\mathrm{T} 8$, with the initial first wave $(\mathrm{N}=3619)$ assessing variables believed to remain stable over time (e.g., stable demographics and motivational orientations). The final sample comprised: $N_{\mathrm{T} 1}=3,118 ; N_{\mathrm{T} 2}=2,531 ; N_{\mathrm{T} 3}=$ 2,002; $N_{\mathrm{T} 4}=1,406 ; N_{\mathrm{T} 5}=1,776, N_{\mathrm{T} 6}=1,520, N_{\mathrm{T} 7}=1,364, N_{\mathrm{T} 8}=1,267$. The increased number of participants from T4 to T5 resulted from an extra effort to regain dropped-out participants at T5: participants were re-invited to T5, T6, T7 and T8 even if they did not complete all of the previous measurement points.

At the start of the study, participants (37\% women) were on average 31.50 years old $(S D=4.59)$. At $\mathrm{T} 1,62.4 \%$ were $\mathrm{PhD}$ students and $37.6 \%$ were $\mathrm{PhD}$ holders. When first taking part in the study, participants varied in their occupational fields: $81.3 \%$ worked at universities or other research institutes, $14.7 \%$ in private industry, $1.0 \%$ in public service, $0.5 \%$ were self-employed, or worked in other/mixed employment $(2.5 \%)$. The majority had non-permanent contracts (75.9\%). By $\mathrm{T} 8$, due to $\mathrm{PhD}$ completion and job change, the percentage of $\mathrm{PhD}$ holders (64.0\%), participants working outside academia (37.9\%) and tenured employees $(46.4 \%)$ had increased. As an incentive for participation, respondents had the opportunity to take part in a lottery winning up to $2000 €(\sim \$ 2.277$ USD; T1 to T8).

\subsection{Measures}

All study variables were measured on 6 -point scales $(1=$ strongly disagree to $6=$ strongly agree). Table 1 displays descriptive statistics, Cronbach's $\alpha$, and correlations between study variables at each measurement point.

To assess work-related self-management, we used three self-generated items: "At the moment, at work, I succeed in concentrating on what is most essential", "Currently, I often invest my time in things at work that are not helpful to my career (recoded)", and "Currently, I manage to organize myself well to move forward in my profession". We developed the items after conducting a review of the literature on work-related self-management that 
showed that there was no appropriate scale assessing self-management at work as it serves vocational development. Therefore, we firstly defined work-related self-management based upon Bandura's (1991) self-regulation theory as a process of successfully pursuing prioritized work-related goals. Next, we generated six items based upon this definition. These items were reviewed for clarity and content validity by two team members of the research project. Four of these items, two sets of two items, overlapped in content, and the redundant item for each pair was eliminated. One item, representing the concept of procrastination, was rejected after not adhering to our definition of work-related self-management. A maximum likelihood exploratory factor analysis (EFA, T1) with varimax rotation revealed a one-factor solution (all item loadings $>.53$ ). The eigenvalue for this factor was 2.04 , accounting for $67.93 \%$ of the total variance.

Please note that our self-management items capture only the dimension of goal pursuit but not of goal selection. Our measure was part of a large multiple-theme survey. Due to time constraints, we had to restrict the numbers of items in the main investigation. We focused on persistent goal pursuit as the corresponding control strategies were assumed to represent a mechanism for dealing with developmental stressors relevant for the achievement of developmental goals (Heckhausen et al., 2010). We then conducted two online questionnaire studies to validate our self-management measure by examining its relationship with theoretically related constructs, namely the use of selective optimization with compensation strategies (SOC; Baltes, Baltes, Freund, \& Lang, 1999), career planning (Gould, 1979), proactive career behaviors (Hirschi, Freund, \& Herrmann, 2014), and constructive thinking strategies (e.g., Manz \& Neck, 2004).

In the first supplementary study we compared our self-management measure with the use of SOC strategies (Baltes et al., 1999), and career planning (Gould, 1979). The SOC model represents an established approach for analyzing general self-management through cognitive and behavioral strategies. Career planning (Gould, 1979) refers to more specific 
career self-management strategies, comprising selection and pursuit of career-related goals. A total of 114 doctoral students ( $46.8 \%$ women; $M=28.12$ years, $S D=3.00)$ from a variety of fields of study (STEM-fields [58.4\%], psychology and cognitive science [28.3\%], cultural studies [8.0\%], economics and law [3.5\%], other/not specified [1.8\%]) were recruited from German universities. Career planning $(\alpha=.85)$ was measured with a six-item scale (Gould, 1979; Wayne, Liden, Kraimer, \& Graf, 1999). A sample item is "I have a plan for my career" (6-point scale, $1=$ strongly disagree, $6=$ strongly agree; $M=3.98, S D=1.14)$. SOC strategies $(\alpha=.80)$ were assessed with the twelve-item SOC scale by Baltes et al. (1999; e.g., "I concentrate all my energy on few things"; 6-point scale, 1 = strongly disagree, $6=$ strongly agree; $M=4.31, S D=0.64)$. As expected, work-related self-management showed moderate positive correlations with career planning $(r=.44, p<.001)$ and with SOC strategies $(r=.43$, $p<.001)$. Furthermore, confirmatory factor analyses (CFA) were conducted using maximum-likelihood estimation with Mplus 7.1 (Muthén \& Muthén, 1998-2015) to test the distinguishability of the measures. The results showed that the three factor model (workrelated self-management, SOC, and career planning; $\chi^{2}(249)=591.85, p<.001 ;$ RMSEA $=$ $.11 ; \mathrm{CFI}=.67 ; \mathrm{TLI}=.63 ; \mathrm{SRMR}=.10)$ provided a better fit to the data (all $p \mathrm{~s}<.001)$ than $(\mathrm{a})$ a one-factor model with all items loading on one factor and (b) two-factor models combining work-related self-management with one of the two scales on one factor. Considering the work-related self-management factor, all three items showed high loadings ranging from .54 to .78 (all $p<.001)$. A maximum likelihood EFA with varimax rotation revealed a one-factor solution (all item loadings $>.60$ ). The eigenvalue for this factor was 2.21 , accounting for $75.53 \%$ of the total variance. Cronbach's alpha of our self-management measure in this supplemental study was .82 .

In the second supplementary study, we examined the association of our selfmanagement instrument with a measure of proactive career behaviors, namely the Career Engagement Scale (Hirschi et al., 2014) and constructive thinking strategies as a 
subdimension of self-leadership (Müller, 2006). The Career Engagement Scale (Hirschi et al., 2014) consists of nine items of which the first three described career management behavior in general (e.g., undertook thinks to achieve one's career goals), while the other six tapped specific career behaviors in terms of career planning, networking, career exploration, positioning behavior, and training. Self-leadership constitutes a specific form of selfregulation. It encompasses different behavior-focused and cognitive strategies. We used the constructive thinking subscales "time planning and will-power activation" and "action planning” of the German Self-Leadership Questionnaire (GSLQ; Müller, 2006, e.g., "I prepare myself carefully before engaging in new activities"; 6-point scale, 1 = strongly disagree, $6=$ strongly agree; $M=4.31, S D=0.64)$. A total of 230 doctoral students and $\mathrm{PhD}$ holders $(25.7 \%, 54.8 \%$ women; $M=32.01$ years, $S D=6.59)$ from a variety of fields of study (STEM-fields [41.3\%], cultural studies and humanities [21.8\%], economics and law [16.5 $\%$ ], medicine [11.7\%], psychology and cognitive science [6.5\%], other/not specified [2.2 \%]) were recruited from German universities. As expected, work-related self-management was moderately associated with proactive career behaviors $(r=.40, p<.001)$, and constructive thinking strategies $(r=.42, p<.001)$. Results of two confirmatory factor analyses (CFA) showed that the three-factor model (work-related self-management, proactive career behaviors, constructive thinking strategies; Model fit: $\chi^{2}(206)=720.58, p<.001$; $\mathrm{RMSEA}=.10 ; \mathrm{CFI}=.78 ; \mathrm{TLI}=.75 ; \mathrm{SRMR}=.10)$ showed a better fit $($ all $p \mathrm{~s}<.001)$ to the data than (a) a one-factor model with all items loading on one (career) self-management factor and (b) two-factor models combining work-related self-management with one of the two scales on one factor. In terms of the factor structure of our self-management instrument, all three items displayed high factor loadings ranging from .59 to .87 (all $p<.001$ ). A maximum likelihood EFA with varimax rotation revealed a one-factor solution (all item loadings $>.64$ ). The eigenvalue for this factor was 2.04 , accounting for $65.95 \%$ of the total variance. Cronbach's alpha of our self-management measure in in this supplemental study was .74. 
In summary, our supplementary studies speak to the validity of our self-management measure. The moderate correlations showed that the constructs were related to though distinct from each other. When interpreting these findings, it is important to note that our measure differs from these existing scales in a number of ways. Measures of career planning and career engagement (Gould, 1979; Hirschi, et al., 2014) focus on the degree of specific career related strategies (e.g., networking, participating in further education). In contrast, our measure assesses the extent to which somebody is successfully pursuing career-related goals at work. Our measure is also different from the self-leadership constructive thinking subscales "time planning and will-power activation" and "action planning” (Müller, 2006) and the use of selective optimization with compensation strategies (SOC; Baltes et al., 1999), in that our measure has a clear career-related focus.

Occupational self-efficacy was measured with a three-item version of the occupational self-efficacy scale (Rigotti et al., 2008): "I can remain calm when facing difficulties in my job because I can rely on my abilities“, "My past experiences in my job have prepared me well for my occupational future", and "I feel prepared for most of the demands in my job". As shown by Rigotti et al. (2008), the scale is one-dimensional and negatively related to job insecurity but positively correlated with job satisfaction, commitment and performance.

For career insecurity, we used three items from a four-item scale developed by Höge et al. (2012): "It is difficult for me to plan my professional future", "I consider my professional development to be secure (recoded)", and "I often wonder how my career will develop". The scale is known to have positive correlations with, for instance, job insecurity, and negative correlations with protean career orientation and well-being (Höge et al., 2012; Spurk, Hirschi, \& Kauffeld, 2016). Based on data from the larger project of which the current study is a part, we additionally determined divergent validity with career satisfaction (Greenhaus, Parasuraman, \& Wormley, 1990; $r=-.35$ ) and job satisfaction (Hackman \& Oldham, 1976; $r=-.31)$. 
Control variables. As previous studies revealed inconsistent differences in career insecurity between men and women, $\mathrm{PhD}$ students and postdocs, and employees in permanent and non-permanent positions (Höge et al., 2012; Ortlieb \& Weiss, 2018), we included gender $(1=$ men, $2=$ women $), \mathrm{PhD}$ status $(1=\mathrm{PhD}, 2=\mathrm{PhD}$ student $)$ and position $(1=$ permanent, 2 $=$ non-permanent $)$ as control variables. Moreover, we included occupational field $(1=$ academia, 2 = other) as a control variable because in our sample, participants from academia reported higher career insecurity but lower self-management and lower self-efficacy than employees from other employment settings (see Table 2).

\subsection{Missing data}

Drop-out analyses did not reveal differences in mean scores for self-management, selfefficacy, and career insecurity at T3 - T8 when comparing respondents with assessments on all eight occasions to those with missing values at one or more time points. However, participants with complete data reported slightly higher career insecurity at T1 and T2 compared to participants who dropped out at one or more waves (T1: $M_{\text {Complete }}=3.92$, $\left.S D_{\text {Complete }}=1.20 ; M_{\text {Drop-out }}=3.79, S D_{\text {Drop-out }}=1.11, t(1177)=2.59, p=.01\right) ; \mathrm{T} 2: M_{\text {Complete }}=$ 3.84, $\left.S D_{\text {Complete }}=1.18 ; M_{\text {Drop-out }}=3.73, S D_{\text {Drop-out }}=1.14, t(2531)=2.10, p=.035\right)$. Next, we computed a binary logistic regression in which the participation pattern (complete vs. missing cases) was regressed on gender, age, $\mathrm{PhD}$ status (doctoral student vs. doctorate holder), contract type (tenure vs. non-tenure), and occupational field at T1. Results showed none of these demographic variables to significantly predict the participation pattern. Since we included variables that predict missing values in our model (career insecurity at T1 and T2), our missing pattern is consistent with a situation of missing at random (MAR). Thus, we employed full information maximum-likelihood (FIML) estimation with robust standard errors to handle missing values. This procedure makes use of all available data points to estimate model parameters under the assumption that data is missing at random (MAR) (Graham, 2009; Enders \& Bandalos, 2001). 


\subsection{Analytical approach}

The analyses were conducted using Mplus 7.1 (Muthén \& Muthén, 1998-2015). A random-intercept cross-lagged panel model (RI-CLPM), an extension of the traditional crosslagged panel model (CLPM), was estimated to control for the stability of individual differences on work-related self-management, occupational self-efficacy, and career insecurity, following the recently suggested approach by Hamaker et al. (2015). The RICLPM represents a "hybrid longitudinal model" as it incorporates autoregressive and crosslagged parameters (CLPM components) and random intercepts (latent growth curve model (LGCM) components) to separate between-person and within-person effects. The main difference between the RI-CLPM and the CLPM is that the RI-CLPM differentiates between individual differences and within fluctuations, and the CLPM does not. Thus, the RI-CLPM represents a multilevel approach that takes into account that measurement occasions are nested within individuals. Unlike the CLPM, in the RI-CLPM random intercepts are added to account for unobserved stable between-person heterogeneity (e.g., time-invariant omitted variables) of repeated measures over the observation period. This means that through the inclusion of these parameters, time-stable characteristics that vary between respondents are ruled out as potential confounds to ensure unbiased cross-lagged estimates at the withinperson level (Hamaker et al., 2015). Instead, in the CLPM it remains unclear whether the cross-lagged paths represent between-person differences or a within-person effect (Keijsers, 2016). Being unable to distinguish between and within-person variance, however, may lead to erroneous conclusions (Hamaker et al., 2015; Keijsers, 2016). From a theoretical viewpoint, we were interested as to whether an individual's improvements in self-management and selfefficacy leads to subsequent reduction of career insecurity over time (within-person process of change) and vice versa. Also, by examining the relationship at a within-person level of analysis, we accounted for self-regulatory processes that vary within individuals as people establish goals, develop strategies, and thereby modify regulatory processes (Sitzmann \& Ely, 
2011). The RI-CLPM splits the observed score variance into variance that represents the individual's stable position in the sample (between-person level) and variance that contains the within-person fluctuation around an individual`s own average level of this measure (expected score). For each individual, an expected score is computed based on the sample mean levels across the eight waves and the individual stable trait factor. The variance at the within-person level represents individuals' deviations from their own expected scores.

As outlined above, the inclusion of the random intercept factors in the RI-CLPM makes it possible to control for time-invariant between-person confounds (e.g., socioeconomic status) so that theses variables can be ruled out as alternative explanations for the significant relationships between the investigated constructs. However, the random intercept factors do not account for time-varying omitted covariates. Thus, it is possible that an omitted time-varying variable would account for the observed associations. In order to control for time-varying third variables, they need to be included in the model (Curran et al., 2014). Theoretically it is impossible to measure all potential time varying confounds (Duckworth, Tsukayama, \& May, 2010). By investigating the interplay of three variables it is at least possible to test whether one of these variable could serve as a common confounding factor that accounts for all associations between the other two variables. In our case, selfefficacy could represent such a confounding factor that potentially fully accounts for any links between career insecurity and self-management. In other words, self-efficacy could lead to both higher self-management and lower career insecurity. It is possible that during career progression individuals gain skills and self-efficacy, which then leads to both higher selfmanagement strategies as well as lower career insecurity. If self-efficacy represents a common confounding factor, any associations between career insecurity and self-management would be invalid and no longer exist.

We specified the RI-CLPM following the procedure described by Hamaker et al., (2015). Thus, we regressed each observed score (mean index of each scale items) on its own 
latent factor, with each loading constrained to 1 . This resulted in eight, within-person latent factors for each of the three constructs, representing the within-person variance (see Figure 2). In a next step, autoregressive paths, cross-lagged paths, covariance at T1 and correlated changes (T2 - T8 correlation) were added between these within-person latent factors. Furthermore, three random intercept factors were included (one for career insecurity, one for self-management, and one for self-efficacy) to account for between-person variance in all three variables. The observed variables were indicators of these random intercept factors, with all factor loadings constrained at 1 . Covariances between these three random factors were added. The error variances of the manifest variables were constrained to be zero to ensure that all of the variance in the observed measures was fully represented by the within-person and between-person latent factors (Keijsers, 2016). Thus, the interpretation of the stability and cross-lagged paths, correlations, and correlated changes estimated in the RI-CLPM is different from those in the CLPM (Keijsers, 2016). The correlation between the random intercepts indicates how stable between-person differences in one variable are associated with stable between-person differences in another variable. The within-person correlation at $\mathrm{T} 1 \mathrm{reflects}$ the extent to which within-person deviations in one variable are associated with deviations from own scores in one of the other variables. The correlated change at waves 2 to 8 expresses the extent to which a within-person change in one variable is linked to a withinperson change in another variable regardless of the association at the previous wave. The stability effects indicate to what extent within-person deviations in career insecurity, selfmanagement, and self-efficacy can be predicted by the individual's prior deviation from the own expected scores. Finally, cross-lagged effects are interpreted as the extent to which changes in someone's personal level of, for example, career insecurity, is predicted by deviation from the own expected scores in self-management or self-efficacy assessed six months earlier (and vice versa) (Hamaker et al., 2015, Keijsers, 2016). Our main interest is in 
the cross-lagged parameters, controlled for by the above-mentioned concurrent correlation of the three variables, their stability over time, and stable between-person differences.

To correct for nonnormality of distribution, we used maximum likelihood estimation with robust errors (Muthén \& Muthén, 1998-2015). Model fit was assessed by Chi square $\left(\chi^{2}\right)$, Tucker-Lewis Index (TLI), the Comparative Fit Index (CFI), and the Root-Mean-Square Error of Approximation (RMSEA), and the Standardized Root Mean Squared Residual (SRMR). A good fit is indicated by RMSEA values of $<0.05$ as well as by CFI and TLI values of $>.95$, and SRMR values of $<0.08$ (Hu \& Bentler, 1999). To investigate differences between models, we used the Satorra-Bentler $\mathrm{Chi}^{2}$ difference test (Satorra \& Bentler, 2001).

In the model building process, we compared the RI-CLPM (M4) with a series of competing models: (1) a stability model (M0) that included within-time correlations and autoregressive effects of each construct; (2) a model which additionally contained the crosslagged paths between self-management and self-efficacy as assumed in Hypotheses 1a and 1b (M1); (3) a model which additionally contained the causal relationship from self-management and self-efficacy to career insecurity as assumed in Hypotheses 2 and 3 (M2); (4) a model which instead additionally contained the reverse effects from career insecurity to selfmanagement and self-efficacy as assumed in Hypotheses 5 and 6 (M3). Finally, to test invariance of the parameters over time, we compared models with unconstrained parameters against models with constrained autoregressive and cross-lagged parameters (M6 and M7). We chose the more parsimonious model, when two models fitted the data equally well (Kline, 2005). If placing equality constraints on stability or cross-lagged paths did not lead to a poorer fitting model, this indicated that the effects were constant across the measurement occasions.

To further test for long-term associations, we additionally ran models with 12 monthtime intervals (including only T1, T3, T5, and T7) and 18 month-time intervals (including only T1, T3, T5, and T7). These analyses enabled us to investigate whether changes in one construct impact changes in one of the other constructs over a longer period of time. For 
example, it is also plausible that self-management exerts a negative effect on career-insecurity not over six months but over longer durations. Additionally, these analyses informed us as to how long lasting an effect of change in one construct on one of the other constructs is. Changes in career insecurity for example may not only affect self-efficacy after six months but may still have an impact a year later. Additionally, indirect effects were examined by using bias-corrected bootstrapped standard errors on the basis of 1000 bootstraps (MacKinnon, Lockwood, \& Williams, 2004). Because bootstrapping cannot be used with the MLR estimator, we applied the maximum likelihood (ML) estimator for these analyses.

\section{Results}

\subsection{Correlations and intra-class correlations}

Means, standard deviations, and correlations for work-related self-management, occupational self-efficacy and career insecurity are reported in Tables 1 and 2. Before running the RI-CLPM, we determined intra-class correlations (ICCs) as an estimate of the withinperson variance of each variable. For career insecurity, ICC was .597. This indicates that $59.7 \%$ of the variance in career insecurity is explained by differences between persons, and that $40.3 \%$ of the variance is explained by fluctuations within a person. Similarly, for occupational self-efficacy, ICC was .588 , indicating that $58.8 \%$ of the variance in selfefficacy is explained by differences between persons. ICC for self-management was .390, indicating that $39.0 \%$ of the variance is explained by between-person variance and $61.0 \%$ by within-person variance. This implies that a substantial part of the variables' variance is due to within-person changes over time, which supports the use of a RI-CLPM (Keijsers, 2016).

\subsection{Measurement invariance of career insecurity, work-related self-management, and} occupational self-efficacy

To examine whether the items were answered and interpreted the same way over the eight measurement waves, we tested for measurement invariance for the three-item measures of career insecurity, self-management, and self-efficacy. We tested for strong factorial 
invariance (factor loadings and intercepts constrained) in comparison to models with configural invariance (no constraints). We added correlated residuals within measurement waves to account for item-level correlations over time, and applied the change in CFI rule as an indicator of invariance, as recommended by Cheung and Rensvold (2002), with a decrease in CFI of $\leq .01$ providing support for the more parsimonious model. Strong factorial invariance was established for all measures (all $\Delta$ CFIs $<.01$; see Table 3).

\subsection{Model comparison}

Fit indices and results of the model comparisons are displayed in Table 4. The model comparison showed that the fit of the full reciprocal model (M4) was significantly better than the fit of any of the other competing models (M0-M3). Since ICCs revealed career insecurity and self-efficacy to have more trait-like qualities, and self-management, instead, to have more state-like characteristics, we tested for a model with random intercept factors for career insecurity and for self-efficacy but not for self-management (M5). The fit of this model was also significantly poorer than of the RI-CLPM (M4), indicating that the RI-CLPM (M4) is the model that best described our data. Next, we added equality constraints on the final reciprocal model. Placing equality constraints on the autoregressive paths of self-efficacy(M6a) and selfmanagement (M6b) did not lead to a loss of fit. But constraining the auto-regressive paths of career insecurity decreased model fit (M6c). Additionally, constraining the cross-lagged paths from self-efficacy to self-management (M7a), and career insecurity (M7b), from selfmanagement to self-efficacy (M7c), and career insecurity (M7d), and from career insecurity to self-management (M7e), and self-efficacy (M7f) did not impair model fit. Thus, the model with constrained auto-regressive self-management and self-efficacy paths, unconstrained auto-regressive career insecurity paths, and all cross-lagged path constrained was chosen as the final model (M7f: $\chi^{2}(231)=534.38, p<.001 ;$ RMSEA $=.020 ;$ CFI $=.982 ;$ TLI $=.985$; SRMR $=.034)$. Standard path coefficients are presented in Figure 3. 


\subsection{Final model}

\subsubsection{Main analyses}

At the between-person level, there were moderately strong correlations between the random intercept factors of self-management and career insecurity $(ß=-.39)$ and self-efficacy and career insecurity $(\beta=-.63, p \mathrm{~s}<.001)$. This indicates that individuals who reported better work-related self-management and higher occupational self-efficacy experienced lower career insecurity across the eight measurement points. The random-intercept factor for selfmanagement was positively related to that for self-efficacy $(\beta=.48, p<.001)$. Thus, higher stable, trait-like levels of self-management were related to higher stable levels of self-efficacy across eight measurement points. At the within-person level, self-management ( $ß \mathrm{~s}=.17$ to $.19)$, self-efficacy ( $(\mathrm{s}=.19$ to .22$)$, and career insecurity ( $\beta \mathrm{s}=.27$ to .51$)$ displayed significant within-person stabilities over time (all $p \mathrm{~s}<.001$ ). Testing H1a and H1b, cross-lagged paths from self-management to self-efficacy ( $ß \mathrm{~s}=.06$ to .07 , all $p \mathrm{~s}<.001)$ as well as all crosslagged effects from self-efficacy to self-management were significant (all $\beta \mathrm{s}=.03$, all $p \mathrm{~s}<$ .05), thus supporting $\mathrm{H} 1 \mathrm{a}$ and $\mathrm{H} 1 \mathrm{~b}$. As expected, an increase in self-management led to a subsequent increase in self-efficacy in the same person (H1a), and an increase in self-efficacy led to a subsequent increase in self-management $(\mathrm{H} 1 \mathrm{~b})$.

Considering the lagged effects from self-management and self-efficacy to career insecurity (H2 and H3), all lagged paths from self-management to career insecurity (ßs $=-.04$ to -.06 , all $p \mathrm{~s}<.001)$ as well as from self-efficacy to career insecurity ( $ß \mathrm{~s}=-.04$ to -.05 , all $p \mathrm{~s}$ $=.001$ ) reached significance, thus supporting $\mathrm{H} 2$ and $\mathrm{H} 3$. An increase in self-management led to a subsequent decrease in career insecurity $(\mathrm{H} 2)$, and an increase in self-efficacy led to a subsequent decrease in career insecurity over time (H3). Additionally, a small, significant specific indirect link from T1 self-management (via T2 self-efficacy) to T3 career insecurity $(\beta=-.003,99 \%$ BcCI [- .001, -.06]) emerged. Thus, supporting H4, self-management at T1 decreased career insecurity at $\mathrm{T} 3$ via increases in self-efficacy at $\mathrm{T} 2$. Indirect effects were also 
tested for the subsequent measurement points, for example, from T2 to T5, from T3 to T6 etc. Results from these analyses correspond with the results from T1 to T3.

Considering the reciprocal relationships, all cross-lagged effects from career insecurity to self-management ( $(\mathrm{s}=-.04$ to -.05 , all $p \mathrm{~s}<.01)$ as well as from career insecurity to selfefficacy ( $\mathrm{s}=-.10$ to -.13 , all $p \mathrm{~s}<.001)$ were significant, thus supporting H5 and H6. An increase in career insecurity led to a subsequent decrease in self-management (H5) and selfefficacy (H6) in the same person. There was no significant indirect effect from T1 career insecurity (via T2 self-efficacy) to T3 self-management ( $\beta=-.003,99 \%$ BcCI $[-.009, .000])$, thus not supporting H7. Indirect effects for the subsequent measurement points (e.g., from T2 to T5, from T3 to T6 etc.) corresponded with these results. A Wald-test indicated that effects from career insecurity to self-efficacy were higher in magnitude than effects from career insecurity to self-management (Wald $(1)=8.286, p<.01)$. Considering the reciprocal relationship of career insecurity and self-efficacy, a second Wald-test indicated that effects from career insecurity to self-efficacy were higher in magnitude than effects from selfefficacy to career insecurity (Wald $(1)=5.776, p<.05$ ). Considering the reciprocal relationship of career insecurity with self-management a third Wald-test indicated that effects from career insecurity to self-management and from self-management to career insecurity did not differ in magnitude (Wald $(1)=0.089, p=.765$ ).

For interpreting effect sizes, it is important to note that these results represent effects after having controlled for trait-like between-person stability. At the within-person level, the explained variance across the eight measurement waves was $R^{2}=.09-.29$ for career insecurity, $R^{2}=.08-.09$ for self-efficacy, and $R^{2}=.04-.05$ for self-management.

\subsubsection{Post-hoc analyses}

To additionally investigate further long-term cross-lagged associations, we tested models with approximately 12 month-time intervals (including only T1, T3, T5, and T7; model fit: $\left.\chi^{2}(38)=66.58, p<.001 ; \mathrm{RMSEA}=.016 ; \mathrm{CFI}=.996 ; \mathrm{TLI}=.993 ; \mathrm{SRMR}=.024\right)$ 
and 18 month-time intervals (including only T1, T4, T7; model fit: $\chi^{2}(11)=15.01, p<.001$; RMSEA $=.011 ; \mathrm{CFI}=.999 ; \mathrm{TLI}=.997 ; \mathrm{SRMR}=.013)$. In both models, we found only small cross-lagged effects from self-management to self-efficacy ( $ß \mathrm{~s}=.09$ to .10 , all $p \mathrm{~s}<.001$ to $<$ .05 ), and from career insecurity to self-efficacy ( $\mathrm{s}_{\mathrm{s}}=-.10$ to -.14 , all $p \mathrm{~s}<.001$ to $<.05$ ). Finally, we estimated the final model (M7f) again while controlling for gender, $\mathrm{PhD}$ status ( $\mathrm{PhD}$ vs. $\mathrm{PhD}$ student), position (permanent vs. non-permanent), and occupational field (academia vs. other). Inclusion of these control variables did not change the overall pattern of results (see Table 5 for cross-lagged paths and stability paths estimates).

\section{Discussion}

The aim of the present study was to investigate the reciprocal relationships between career insecurity, work-related self-management, and occupational self-efficacy. Based on the motivational theory of life-span development (MTD; Heckhausen et al., 2010) and the notion of triadic reciprocity in social cognitive theory of self-regulation (SCT; Bandura, 1986, 1997), we investigated the existence of bidirectional links between the three constructs using an 8wave repeated-measures design with time lags of approximately 6 months. To study withinperson effects, we used the recently introduced RI-CLPM (Hamaker et al., 2015). This novel model allows separating the within-person process from stable, between-person differences through the inclusion of random intercepts.

At the between-person level, career insecurity and work-related self-management as well as career insecurity and occupational self-efficacy were negatively correlated. This indicates that young scientists who reported more efficient self-management and higher selfefficacy across the eight measurement points also experienced lower career insecurity across the eight occasions. Moreover, self-management and self-efficacy were positively correlated, indicating that individuals who reported more efficient self-management across the eight measurement points also experienced more self-efficacy. 
At the within-person level, as expected, results showed negative cross-lagged effects from self-management and self-efficacy to career insecurity as well as negative cross-lagged paths from career insecurity to self-management and self-efficacy. Also, self-efficacy and self-management were positively related at the within-person level, although to a modest degree. The results of our study supported our main research assumption: They showed a pattern of reciprocal causation, which is in line with the idea of triadic reciprocal causation that is central to SCT theory. The separation of within-person from between-person variance allows us to conclude that intra-individual increases in self-management and self-efficacy lead to a subsequent decrease of perceived career insecurity, which in turn leads to a subsequent strengthening of self-management and self-efficacy. Our 8-wave longitudinal design offered us the possibility to examine long-term processes over different durations. Testing models with 12 month-time intervals (including T1, T3, T5, and T7) and 18 month-time intervals (including T1, T4, T7), however, showed only significant cross-lagged effects from selfmanagement to self-efficacy and from career insecurity to self-efficacy for both models. This indicates that effects of career insecurity and self-management on self-efficacy are more consistent even over longer durations.

These results help to explain by which mechanisms self-efficacy and self-management are most likely to have an impact on career insecurity, and vice versa. Past research showed that self-management strategies and self-efficacy beliefs are associated with objective and subjective career success (e.g., Abele \& Wiese, 2008; Spurk \& Abele, 2014). Because, especially in academia, it takes a long time until objective career success occurs, it seems unlikely that actual career achievement (e.g., becoming full professor) would be the dominant mechanism by which self-management and self-efficacy reduced career insecurity. It seems more plausible that through experiencing more efficient self-management and enhanced selfefficacy beliefs, young scientists may have experienced greater control over their jobs and thus might have felt to be more in control of their careers, too. This coincides with previous 
research showing perceived control to be an important mechanism for coping with workplace stress arising from uncertainty (Ito \& Brotheridge, 2001; Vander Elst et al., 2012). Similarly, in past research, self-efficacy was shown to buffer the negative effect of job insecurity on employees' work engagement and well-being (Guarnaccia, Scrima, Civilleri, \& Salerno, 2018).

As further expected, our results showed that within-person deviations from an individual's trait level of career insecurity predicted subsequent changes in self-efficacy beliefs and self-management activities. A plausible interpretation is that career insecurity creates stress and anxiety, thereby reducing an individual's ability to set and persistently pursue adequate goals (Colakoglu, 2011). An alternative explanation could be that career insecurity induces an action crisis, a personal conflict in which the individual is torn between engaging and distancing from goals (Brandstätter, Herrmann, \& Schüler, 2013). Finally, such a crisis might lead to disengagement from goals, resulting in lowered self-management activity and lower self-efficacy beliefs.

Although most of these within-person effects are modest in magnitude, it is important to note that these associations still remain after having controlled for the trait-like stability (through the inclusion of random intercepts as proposed by Hamaker et al., 2015). Also, such effects need to be interpreted within the context of longitudinal designs as controlling for autoregressive effects substantially diminishes the magnitude of effect sizes between predictors and outcomes (Adachi \& Willoughby, 2015). Moreover, even small effects can still be meaningful when predicting change in the outcome variable as they may represent cumulative or cascading effects and thus impact the outcome over a longer period of time (Abelson, 1985; Adachi \& Willoughby, 2015). Hence, the influence of self-management and self-efficacy on career insecurity, and vice versa, may be more substantial over multiple years. 


\subsection{Theoretical contributions}

By investigating reciprocal relationships of career insecurity, career self-management, and occupational self-efficacy, our study contributes to testing the central assumption of triadic reciprocity of SCT (Bandura, 1986, 1991, 1997). Our results support SCT theory in that individual behavior and personal beliefs are reciprocally related (Bandura, 1986, 1997). Thus, our results are in line with previous findings on self-efficacy and performance (e.g., Shea \& Howell, 2000; Williams \& Williams, 2010). At the same time, our research advances literature on bidirectional processes in SCT: By integrating career insecurity as a further internal factor (in addition to self-efficacy) that at the same time is strongly influenced by environmental factors, we could investigate how these two factors are interconnected and how they differ in their relationship with self-management.

Moreover, by considering career-related concerns, we respond to calls to take a longterm perspective as compared to typical laboratory studies on task performance (Day \& Unsworth, 2013). Furthermore, our longitudinal design allowed the investigation of the dynamic relationship of our constructs in a naturalistic work setting. Bandura and Locke (2003) argue that longitudinal field studies are needed to supplement experimental studies in self-regulation research by integrating the complex interplay of socio-structural and personal factors. Contrary to experimental repeated measures designs having shown self-efficacy to exert no or even a negative effect on performance at the within-person level (Sitzmann \& Yeo, 2013, Yeo \& Neal, 2006), we found individuals who experience an increase in selfefficacy relative to their baseline level across all waves to show a subsequent increase in selfmanagement activity relative to their underlying level in self-management. This strengthens the assertion that the within-person relationship of self-regulation and self-efficacy in naturalistic settings develops a different dynamic compared to those in experimental settings (Bandura \& Locke, 2003; Tierney \& Farmer, 2011). 
With regard to our theoretical understanding of career insecurity, the reciprocal pattern of our results supports the notion that career insecurity is connected to a lack of control. Previous research conceptualized career insecurity as powerlessness concerning the attainment of employability or individual career goals (Colakoglu, 2011; Höge et al., 2012). By providing evidence for its dynamic relationship with career-related control strivings (selfmanagement) and control beliefs (self-efficacy), our results strengthen this assumption.

The current study's within-person focus contributes to the career insecurity literature by being the first to show that, on an intra-individual level, career insecurity and selfmanagement/self-efficacy affect each other reciprocally. Previous studies investigating other proactive constructs' associations with career insecurity did not differentiate within-person from between-person effects (e.g., career adaptability, Spurk et al., 2016). A between-person design cannot account for intra-individual effects but instead describes whether differences between individuals in one construct are associated with differences in individuals in the other construct. Thus, between-person analyses are suitable for other research questions, for instance, when the goal is to detect how individuals differ in their coping strategies related to career insecurity. However, it may be an inadequate analysis strategy when investigating psychological constructs that exhibit change over time within one person (Voelkle, Brose, Schmiedek, \& Lindenberger, 2014). The present findings underscore the necessity to use appropriate analytical methods that are adapted to the theoretically-derived research hypotheses (Curran et al., 2014).

By showing that an increase in career insecurity presents a risk for subsequent decreases in self-management and self-efficacy, our study provides insight in factors that could impede the occurrence of agentic behavior. Past research neglected factors that could hamper the motivation to engage in career self-management but instead concentrated mainly on its positive consequences (Briscoe et al., 2012; Hall \& Mirvis, 1996). 


\subsection{Strengths, limitations, and implications for future research}

Our study has several strengths, including the large sample size, eight measurement waves, and a sophisticated approach for modeling longitudinal data (i.e., Hamaker et al., 2015). Methodologically, by using the RI-CLPM, we were able to demonstrate for the first time that increases in self-management predict decreases in career insecurity via increases in self-efficacy and that increases in career insecurity precede decreases in self-management and self-efficacy.

This study is not without limitations. Our sample was limited to highly educated respondents from STEM fields. Moreover, our sample was probably not representative of typical $\mathrm{PhD}$ students and scientists, as we used a mix of recruitment strategies. Future research is necessary to replicate the present findings with other samples, including scientists from other fields (e.g., social sciences and humanities) as well as (less educated) employees outside of academia.

Our conceptual choice of time lags of 6 months is limited when it comes to revealing the real time effect pattern of the underlying reciprocal relationship. As mentioned above, our 8-wave longitudinal design offered us an excellent opportunity to examine long-term processes over different durations. However, as we accounted for shorter time lags, we could not test effects that evolve shorter period of times (e.g., 3 months). Future within-person investigation is needed to further address this point. Moreover, we cannot be sure which period of time participants had in mind while answering our self-management questions. Since the items of our measure use phrases like "currently", it cannot be ruled out that reports of levels of work-related self-management at the moment or day were solicited. In our view, however, because the questionnaire was distributed in half-year intervals, the majority of native German speakers would have likely interpreted the German word for "currently" (gegenwärtig) to represent a time period of more than a day. This is further supported by the intra-class correlations (ICC) of .39, and the fact that the inclusion of a random intercept for 
self-management in our RI-CLPM improved model fit. Likewise, the variance of the random intercept for self-management $(\mathrm{Var}=0.35, p>.001)$ reached significance, indicating that this variable is to some extent characterized by stable between-person differences. Together this suggests that our conceptualization of self-management has a trait component, although it certainly is less stable than self-efficacy and career insecurity.

From a process point of view, future research should test in more detail if our pattern of results changes when taking into account critical transitions that go along with different levels of career insecurity, for instance, the successful completion of a $\mathrm{PhD}$. Initial descriptive results from the data used in this study showed an increase in career insecurity shortly preceding $\mathrm{PhD}$ completion and a decrease in career insecurity immediately following the transition to a postdoc position. A possible explanation is that the event of $\mathrm{PhD}$ completion is associated with a gain in resources. Hence, future research should focus on how major life events influence career insecurity and its relationship with self-management and self-efficacy.

Another aspect that might be optimized in the future is the conceptualization and measurement of career insecurity and self-management. Using the scale developed by Höge et al. (2012), we measured career insecurity as an individual's insecurity about the achievement of subjective career goals. This implicitly assumes that young scientists are aware of their career goals (Ortlieb \& Weiss, 2018). The selection of adequate goals represents in itself a source of insecurity for individuals in highly uncertain work environments (Trevor-Roberts, 2006). Moreover, past research pointed out that many $\mathrm{PhD}$ students are not sure whether to pursue an academic career after PhD completion or not (e.g., Roach \& Sauermann, 2010). Future studies should take this indecisiveness into consideration and connect career insecurity to career goal selection and commitment.

In the same vein, measures of self-management should include goal-selection facets. Our research supports the assumption that career insecurity impedes the pursuit of goals. However, since our self-management measure did not comprise items referring to goal 
selection, we can only speculate as to whether perceptions of career insecurity are influenced by the selection of goals or likewise represent a barrier for goal choice. MTD assumes that goal engagement strategies are particularly important for dealing with developmental demands (Heckhausen et al., 2010). Given that processes of goal setting and goal pursuit are interdependent and functionally related (Achtziger \& Gollwitzer, 2018), it is reasonable to focus on both dimensions instead of just one in future research. We assume that career insecurity is associated with goal selection as well, albeit to a lesser extent. Goal selection is just the first step in the course of action and requires several different subsequent tasks to be mastered. Nevertheless, career insecurity could impair an individual's confidence in being committed to the right goal. Indeed, research already showed career insecurity to be a predictor of the intention to leave academia (e.g., Dorenkamp \& Weiß, 2017).

Through our conceptualization of self-management, we chose a relatively broad approach by focusing on the pursuit of prioritized work-related goals. Future research might include more specifically volitional self-management strategies, such as action and time planning or dealing with setbacks and disruptions.

Moreover, future research could examine the incremental validity of career selfmanagement with regard to other related agentic constructs that have been argued to be helpful in coping with career insecurity, such as career adaptability (e.g., Spurk et al., 2016). Drawing on the MTD (Heckhausen et al., 2010), we expected career self-management strategies (in terms of active and focused attempts to achieve a career goal) to be the primary adaptive response for young scientists when confronted with career insecurity. However, as adjusting one's goals to changing opportunities and constraints might also be required in longterm development processes and the further course of action (Heckhausen et al., 2010), it seems promising to investigate whether and how persistent goal striving and flexible goal adjustment operate together (e.g., if the deadline for getting a tenured professorship position has nearly passed). All in all, our findings emphasize the need for more longitudinal studies to 
enhance our understanding of other constructs that contribute to changes in career insecurity over time.

Another limitation is that, although we could establish strong factorial invariance in our measures, we could not employ a multiple indicator version of the RI-CLPM (MI-RICLPM, Hamaker, 2018) to control for measurement error. In the case of our data, the MICLPM did not converge. This convergence problem was probably caused by the complexity of our model consisting of three constructs and eight measurement points. Other researchers also report difficulties in combining the RI-CLPM with a measurement model, such as converging problems or conflation of within-person and between-person variance (Krauss, Orth, \& Robins, 2019; Masselink et al., 2018). We assume that it is for this reason that the vast majority of researchers who apply RI-CLPMs rely on the practice of using mean scores instead of factor models. It is an important challenge for future methods research to investigate how RI-CLPM can be reliably extended to comprise measurement models. An alternative would be the development of other modeling approaches for disentangling measurement error from within-person error in longitudinal designs.

Finally, by employing the RI-CLPM (Hamaker et al., 2015), we could control for all time-invariant, between-individual confounds. However, it is still possible that omitted timevarying variables influenced our results. Further studies should additionally control for variables (e.g., self-esteem) that vary over time and are likely to be related to selfmanagement/self-efficacy and career insecurity.

\subsection{Practical implications}

It is important to acknowledge that career insecurity reduces self-management and self-efficacy. Previous research has concentrated largely on the positive consequences of career self-management and other proactive behaviors for today's insecure career environments (Briscoe et al., 2012; Hall \& Mirvis, 1996). What is most challenging is that while agency (beliefs) reduce insecurity, insecurity undermines self-management attempts 
and self-efficacy beliefs. In other words, the individual resources required to deal with career insecurity run the risk of decreasing due to this insecurity itself. Therefore, it is highly desirable to offer more reliable career paths for young scholars. But given that structural constraints within the academic career environment are not easily malleable, objective career security in academia cannot be simply increased. Hence, from a practical point of view, attention should be paid to enhancement in self-management activity and occupational selfefficacy to partly compensate for the diminishing effect of career insecurity. In our view, it is important to prevent an individual from entering into a downward spiral marked by low engagement in career goals and high perceived career insecurity. Considering that past research has shown self-management as well as self-efficacy to be trainable (e.g., Frayne \& Latham, 1987; Schmitz \& Wiese, 2006), young scientists might profit from coaching or trainings focusing on self-management and competence-related self-reflection, which, in turn, should also lead to an increase in self-efficacy. By engaging in agentic behavior, individuals can proactively avoid ruminating about career insecurity and enhance the perception of control over their careers.

\subsection{Concluding remarks}

In summary, by showing the negative relation between perceived career insecurity and work-related self-management as well as occupational self-efficacy in academia, our results add support to the notion of Hall and Las Heras (2010) that job-related and career-related concepts are strongly associated and should be brought together to enhance our understanding of careers. Moreover, methodologically, the necessity of longitudinal designs in career research has been acknowledged for many years. But we also need adequate modeling approaches to actually grasp the longitudinal interplay of our concepts of interest. Taking into account that change processes operate within the individual, the RI-CLPM approach could advantageous for career researchers, as it offers a particularly adequate approach to crosslagged modeling of developmental processes. 


\section{References}

Abele, A. E., \& Wiese, B. S. (2008). The nomological network of self-management strategies and career success. Journal of Occupational and Organizational Psychology, 81, 733749. doi:10.1348/096317907X256726

Abelson, R. P. (1985). A variance explanation paradox: When a little is a lot. Psychological Bulletin, 97, 129-133.

Achtziger, A., \& Gollwitzer, P. M. (2018). Motivation and volition in the course of action. In J. Heckhausen \& H. Heckhausen (Eds.), Motivation and action (3nd edition; pp. 485527). London: Cambridge University Press. https://doi.org/10.1007/978-3-319-650944_12.

Adachi, P., \& Willoughby, T. (2015). Interpreting effect sizes when controlling for stability effects in longitudinal autoregressive models: Implications for psychological science. European Journal of Developmental Psychology, 12, 116-128. doi:10.1080/17405629.2014.963549

Baltes, P. B., Baltes, M. M., Freund, A. M., \& Lang, F. (1999). The measurement of selection, optimization, and compensation (SOC) by self-report: Technical report. Berlin, Germany: Max Planck Institute for Human Development.

Bandura, A. (1986). Social foundation of thought and action: A social-cognitive theory. Englewood Cliffs, NJ: Prentice Hall.

Bandura, A. (1991). Social cognitive theory of self-regulation. Organizational Behavior and Human Decision Processes, 50(2), 248-287. doi:10.1016/0749-5978(91)90022-L

Bandura, A. (1997). Self-efficacy: The exercise of control. New York: Freeman.

Bandura, A., \& Locke, E. A. (2003). Negative self-efficacy and goal effects revisited. Journal of Applied Psychology, 88, 87-99. doi:10.1037/0021-9010.88.1.87

Baruch, Y., \& Hall, D. T. (2004). The academic career: A model for future careers in other sectors? Journal of Vocational Behavior, 64, 241-262. doi:10.1016/j.jvb.2002.11.002 
Brandstätter, V., Herrmann, M., \& Schüler, J. (2013). The struggle of giving up personal goals: Affective, physiological, and cognitive consequences of an action crisis. Personality and Social Psychology Bulletin, 39, 1668-1682. doi:10.1177/0146167213500151

Bredehöft, F., Dettmers, J., Hoppe, A., \& Janneck, M. (2015). Individual work design as a job demand: The double-edged sword of autonomy. Journal of Everyday Activity, 8, 1326.

Briscoe, J. P., Henagan, S. C., Burton, J. P., \& Murphy, W. M. (2012). Coping with an insecure employment environment: The differing roles of protean and boundaryless career orientations. Journal of Vocational Behavior, 80, 308-316. doi:0.1016/j.jvb.2011.12.008

Chamandy, M., \& Gaudreau, P. (2019). Career doubt in a dual-domain model of coping and progress for academic and career goals. Journal of Vocational Behavior, 110, 155167. doi:10.1016/j.jvb.2018.11.008

Cheung, G. W., \& Rensvold, R. B. (2002). Evaluating goodness-of-fit indexes for testing measurement invariance. Structural Equation Modeling, 9, 233-255. doi:10.1207/S15328007SEM0902_5

Colakoglu, S. N. (2011). The impact of career boundarylessness on subjective career success: The role of career competencies, career autonomy, and career insecurity. Journal of Vocational Behavior, 79, 47-59. doi:10.1016/j.jvb.2010.09.011

Curran, P. J., Howard, A. L., Bainter, S. A., Lane, S. T., \& McGinley, J. S. (2014). The separation of between-person and within-person components of individual change over time: A latent curve model with structured residuals. Journal of Consulting and Clinical Psychology, 82, 879-894. doi:0.1037/a0035297

Day, D. V., \& Unsworth, K. L. (2013). Goals and self-regulation: Emerging perspectives across levels and time. In E. A. Locke \& G. P. Latham (Eds.), New developments in 
goal setting and task performance (pp. 158-176). New York, NY: Routledge, Taylor \& Francis Group.

De Witte, H. (2005). Job insecurity: Review of the international literature on definitions, prevalence, antecedents and consequences. SA Journal of Industrial Psychology, 31, 16.

Dorenkamp, I., \& Weiß, E. E. (2017). What makes them leave? A path model of postdocs' intentions to leave academia. Higher Education, 75, 747-767. doi:10.1007/s10734017-0164-7

Duckworth, A. L., Tsukayama, E., \& May, H. (2010). Establishing causality using longitudinal hierarchical linear modeling: An illustration predicting achievement from self-control. Social Psychological and Personality Science, 1, 311-317. doi:10.1177/1948550609359707

Enders, C. K., \& Bandalos, D. L. (2001). The relative performance of full information maximum likelihood estimation for missing data in structural equation models. Structural Equation Modeling, 8, 430-457.doi:10.1207/S15328007SEM0803_5

Etehadi, B., \& Karatepe, O. M. (2018). The impact of job insecurity on critical hotel employee outcomes: The mediating role of self-efficacy. Journal of Hospitality Marketing \& Management, 28, 1-25. doi:10.1080/19368623.2019.1556768

Frayne, C. A., \& Latham, G. P. (1987). Application of social learning theory to employee self-management of attendance. Journal of Applied Psychology, 72, 387-392. doi:10.1037/0021-9010.72.3.387

Garcia, P. R. J. M., Restubog, S. L. D., Bordia, P., Bordia, S., \& Roxas, R. E. O. (2015). Career optimism: The roles of contextual support and career decision-making selfefficacy. Journal of Vocational Behavior, 88, 10-18. doi: 10.1016/j.jvb.2015.02.004 
Grümer, S., Silbereisen, R. K., \& Heckhausen, J. (2013). Subjective well-being in times of social change: Congruence of control strategies and perceived control. International Journal of Psychology, 48, 1246-1259. doi:10.1080/00207594.2012.744839

Goller, M. (2017). Human agency at work: An active approach towards expertise development. Wiesbaden, Germany: Springer VS.

Gollwitzer, P. M. (1990). Action phases and mind-sets. In E. T. Higgins \& R. M. Sorrentino (Eds.), Handbook of motivation and cognition: Foundations of social behavior (pp. 53-92). New York, NY: Guilford Press.

Gollwitzer, P. M. (2012). Mindset theory of action phases. In P. Van Lange, A. W. Kruglanski \& E. T. Higgins (Eds.), Handbook of theories of social psychology (pp. 526-545). London, England: Sage.

Gould, S. (1979). Characteristics of career planners in upwardly mobile occupations. Academy of Management Journal, 22, 539-550. doi: 10.5465/255743

Graham, J. W. (2009). Missing data analysis: Making it work in the real world. Annual Review of Psychology, 60, 549-576. doi:10.1146/annurev.psych.58.110405.085530

Greenhalgh, L., \& Rosenblatt, Z. (1984). Job insecurity: Toward conceptual clarity. Academy of Management Review, 3, 438-448. doi:10.5465/amr.1984.4279673

Greenhaus, J. H., Parasuraman, S., \& Wormley, W. M. (1990). Effects of race on organizational experiences, job performance evaluations, and career outcomes. Academy of Management Journal, 33, 64-86. doi:10.5465/256352

Guarnaccia, C., Scrima, F., Civilleri, A., \& Salerno, L. (2018). The role of occupational selfefficacy in mediating the effect of job insecurity on work engagement, satisfaction and general health. Current Psychology, 37, 488-497. doi:10.1007/s12144-016-9525-0

Hackman, J. R., \& Oldham, G. R. (1976). Motivation through the design of work: Test of a theory. Organizational Behavior and Human Performance, 16, 250-279. doi:10.1002/job.613 
Hall, D. T. (2002). Careers in and out of organizations. Thousand Oaks, CA: Sage. doi:10.4135/9781452231174.n1

Hall, D. T., \& Las Heras, M. L. (2010). Reintegrating job design and career theory: Creating not just good jobs but smart jobs. Journal of Organizational Behavior, 31, 448-462. doi:10.1002/job.613

Hall, D. T., \& Mirvis, P. H. (1996). The new protean career: Psychological success and the path with a heart. In D. T. Hall \& Associates (Eds.), The career is dead - Long live the career: A relational approach to careers (pp. 14-45). San Francisco, CA: Jossey-Bass.

Hamaker, E. L. (2018). How to run a multiple indicator RI-CLPM with Mplus. Retrieved from http://www.statmodel.com/download/RI-CLPM.pdf

Hamaker, E. L., Kuiper, R. M., \& Grasman, R. P. (2015). A critique of the cross-lagged panel model. Psychological Methods, 20, 102-116. doi:10.1037/a0038889

Harley, S., Muller-Camen, M., \& Collin, A. (2004). From academic communities to managed organisations: The implications for academic careers in UK and German universities. Journal of Vocational Behavior, 64, 329-345. doi:10.1016/j.jvb.2002.09.003

Heckhausen, J. (2010). Globalization, social inequality, and individual agency in human development: Social change for better or worse? In R. K. Silbereisen \& X. Chen (Eds.), Social change and human development: Concept and results (pp. 148-163). Los Angeles, CA: Sage.

Heckhausen, H., \& Gollwitzer, P. M. (1987). Thought contents and cognitive functioning in motivational versus volitional states of mind. Motivation and Emotion, 11, 101-120. doi: 10.1007/BF00992338

Heckhausen, J., Wrosch, C., \& Schulz, R. (2010). A motivational theory of life-span development. Psychological Review, 117, 32-60. doi:10.1037/a0017668. 
Hirschi, A., Freund, P. A., \& Herrmann, A. (2014). The career engagement scale: Development and validation of a measure of proactive career behaviors. Journal of Career Assessment, 22, 575-594. doi:1177/1069072713514813

Hirschi, A., Lee, B., Porfeli, E. J., \& Vondracek, F. W. (2013). Proactive motivation and engagement in career behaviors: Investigating direct, mediated, and moderated effects. Journal of Vocational Behavior, 83, 31-40. doi: 10.1016/j.jvb.2013.02.003

Höge, T., Brucculeri, A., \& Iwanowa, A. N. (2012). Karriereunsicherheit, Zielkonflikte und Wohlbefinden bei Nachwuchswissenschaftlerinnen und -wissenschaftlern [Career insecurity, goal conflicts, and well-being among young scientists: A study in three countries]. Zeitschrift für Arbeits- und Organisationspsychologie, 56, 159-172. doi:10.1026/0932-4089/a000088

Hu, L., \& Bentler, P. M. (1999). Cutoff criteria for fit indexes in covariance structure analysis: Conventional criteria versus new alternatives. Structural Equation Modeling, 6, 1-55. doi:10.1080/10705519909540118

Ito, J. K., \& Brotheridge, C. M. (2001). An examination of the roles of career uncertainty, flexibility, and control in predicting emotional exhaustion. Journal of Vocational Behavior, 59, 406-424. doi:10.1006/jvbe.2001.1800.

Keijsers, L. (2016). Parental monitoring and adolescent problem behaviors: How much do we really know? International Journal of Behavioral Development, 40, 271-281. doi:10.1177/0165025415592515

King, Z. (2004). Career self-management: Its nature, causes and consequences. Journal of Vocational Behavior, 65, 112-133. doi:10.1016/S0001-8791(03)00052-6

Kinman, G., \& Jones, F. (2008). Effort-reward imbalance and overcommitment: Predicting strain in academic employees in the United Kingdom. International Journal of Stress Management, 15, 381-395. doi:10.1037/a0013213 
Klehe, U. C., Zikic, J., Van Vianen, A. E., \& De Pater, I. E. (2011). Career adaptability, turnover and loyalty during organizational downsizing. Journal of Vocational Behavior, 79, 217-229. doi:10.1016/j.jvb.2011.01.004

Kline, R. B. (2005). Principles and practice of structural equation modeling (2nd edition). New York, NY: Guilford.

Körner, A., Lechner, C. M., Pavlova, M. K., \& Silbereisen, R. K. (2015). Goal engagement in coping with occupational uncertainty predicts favorable career-related outcomes. Journal of Vocational Behavior, 88, 174-184. doi:10.1016/j.jvb.2015.03.001

Kossek, E. E., Roberts, K., Fisher, S., \& Demarr, B. (1998). Career self-management: A quasi-experimental assessment of the effects of a training intervention. Personnel Psychology, 51, 935-960. doi: 10.1111/j.1744-6570.1998.tb00746.x

Krauss, S., Orth, U., \& Robins, R. W. (2019). Family environment and self-esteem development: A longitudinal study from age 10 to 16. Journal of Personality and Social Psychology. Advance online publication. doi:10.1037/pspp0000263

Lechner, C. M., Tomasik, M. J., \& Silbereisen, R. K. (2016). Preparing for uncertain careers: How youth deal with growing occupational uncertainties before the education-to-work transition. Journal of Vocational Behavior, 95, 90-101. doi:10.1016/j.jvb.2016.08.002

Lord, R. G., Diefendorff, J. M., Schmidt, A. M., \& Hall, R. J. (2010). Self-regulation at work. Annual Review of Psychology, 61, 543-568. doi:10.1146/annurev.psych.093008.100314

MacKinnon, D. P., Lockwood, C. M. \&. Williams, J. (2004). Confidence limits for the indirect effect: Distribution of the product and resampling methods. Multivariate Behavioral Research, 39, 99-128. doi:10.1207/s15327906mbr3901_4

Manz, C. C. \& Neck, C. P. (2004). Mastering self-leadership: Empowering yourselffor personal excellence ( $3^{\text {rd }}$ ed.). Englewood Cliffs, NJ: Prentice-Hall. 
Mauno, S., Leskinen, E., \& Kinnunen, U. (2001). Multi-wave, multi-variable models of job insecurity: applying different scales in studying the stability of job insecurity. Journal of Organizational Behavior, 22, 919-937. doi:10.1002/job.122

Masselink, M., Van Roekel, E., Hankin, B. L., Keijsers, L., Lodder, G. M. A., Vanhalst, J., Verhagen, M., Young, J. F., \& Oldehinkel, A. J. (2018). The longitudinal association between self-esteem and depressive symptoms in adolescents: Separating betweenperson effects from within-person effects. European Journal of Personality, 32, 653671. doi:10.1002/per.2179

Mirvis, P. H., \& Hall, D. T. (1996). Psychological success and the boundaryless career. In M. B. Arthur \& D. M. Rousseau (Eds.), The boundaryless career: a new employment principle for a new organizational era (pp. 237-255). Oxford, UK: Oxford University Press.

Muthén, L. K., \& Muthén, B. O. (1998-2015). Mplus user's guide (7th ed). Los Angeles, CA: Muthén \& Muthén.

Müller, G. F. (2006). Dimensions of self-leadership: A German replication and extension. Psychological Reports, 99, 357-362. doi:10.2466/pr0.99.2.357-362

Ortlieb, R., \& Weiss, S. (2018). What makes academic careers less insecure? The role of individual-level antecedents. Higher Education, 76, 571-587. doi:10.1007/s 10734-017-0226-x

Pajares, F. (1997). Current directions in self-efficacy research. In M. Maehr \& P. R. Pintrich (Eds.), Advances in Motivation and Achievement (Vol. 10, pp. 1-49). Greenwich, CT: JAI Press.

Rigotti, T., Schyns, B., \& Mohr, G. (2008). A short version of the occupational self-efficacy scale: Structural and construct validity across five countries. Journal of Career Assessment, 16, 238-255. doi:10.1177/1069072707305763 
Roach, M., \& H. Sauermann, (2010). A taste for science? PhD scientists' academic orientation and self-selection into research careers in industry. Research Policy, 39, 422-434. doi:10.1016/j. respol.2010.01.004

Satorra, A., \& Bentler, P. M. (2001). A scaled difference chi-square test statistic for moment structure analysis. Psychometrika, 66, 507-514. doi: 10.1007/BF02296192

Schmitz, B., \& Wiese, B. S. (2006). New perspectives for the evaluation of training sessions in self-regulated learning: Time-series analyses of diary data. Contemporary Educational Psychology, 31, 64-96. doi: 10.1016/j.cedpsych.2005.02.002

Schwab, K. (2016). The fourth industrial revolution. New York, NY: Crown Business.

Shea, C. M., \& Howell, J. M. (2000). Efficacy-performance spirals: An empirical test. Journal of Management, 26, 791-812. doi:10.1177/014920630002600409

Sitzmann, T., \& Ely, K. (2011). A meta-analysis of self-regulated learning in work-related training and educational attainment: What we know and where we need to go. Psychological Bulletin, 137, 421-442. doi:10.1037/a0022777

Sitzmann, T., \& Yeo, G. (2013). A meta-analytic investigation of the within-person selfefficacy domain: Is self-efficacy a product of past performance or a driver of future performance? Personnel Psychology, 66, 531-568. doi:10.1111/peps.12035

Skinner, E. A. (1997). Planning and perceived control. In S. L. Friedman \& E. K. Scholnick, (Eds.), The developmental psychology of planning: Why, how, and when do we plan? (pp. 263-284). Mahwah, NJ: Erlbaum.

Spurk, D., \& Abele, A. E. (2014). Synchronous and time-lagged effects between occupational self-efficacy and objective and subjective career success: Findings from a four-wave and 9-year longitudinal study. Journal of Vocational Behavior, 84, 119-132. doi:10.1016/j.jvb.2013.12.002 
Spurk, D., Hirschi, A., \& Kauffeld, S. (2016). A new perspective on the etiology of workaholism: The role of personal and contextual career-related antecedents. Journal of Career Assessment, 24, 747-764. doi:10.1177/1069072715616127

Spurk, D., Kauffeld, S., Meinecke, A. L., \& Ebner, K. (2016). Why do adaptable people feel less insecure? Indirect effects of career adaptability on job and career insecurity via two types of perceived marketability. Journal of Career Assessment, 24, 289-306. doi:10.1177/1069072715580415

Steel, P. (2007). The nature of procrastination: A meta-analytic and theoretical review of quintessential self-regulatory failure. Psychological Bulletin, 133, 65-94. doi:10.1037/0033-2909.133.1.65

Tierney, P., \& Farmer, S. M. (2011). Creative self-efficacy development and creative performance over time. Journal of Applied Psychology, 96, 277-292. doi:10.1037/a0020952

Trevor-Roberts, E. (2006). Are you sure? The role of uncertainty in career. Journal of Employment Counseling, 43, 98-116. doi:10.1002/j.2161-1920.2006.tb00010.x Vander Elst, T., Van den Broeck, A., De Witte, H., \& De Cuyper, N. (2012). The mediating role of frustration of psychological needs in the relationship between job insecurity and work-related well-being. Work \& Stress, 26, 252-271. doi:10.1080/02678373.2012.703900

Van Hootegem, A., \& De Witte, H. (2019). Qualitative job insecurity and informal learning: A longitudinal test of occupational self-efficacy and psychological contract breach as mediators. International Journal of Environmental Research and Public Health, 16, 1847-1871. doi:10.3390/ijerph16101847.

Voelkle, M. C., Brose, A., Schmiedek, F., \& Lindenberger, U. (2014). Toward a unified framework for the study of between-person and within-person structures: Building a 
bridge between two research paradigms. Multivariate Behavioral Research, 49, 193213. doi:10.1080/00273171.2014.889593

Wäschle, K., Allgaier, A., Lachner, A., Fink, S., \& Nückles, M. (2014). Procrastination and self-efficacy: Tracing vicious and virtuous circles in self-regulated learning. Learning and Instruction, 29, 103-114. doi:10.1016/j.learninstruc.2013.09.005

Wayne, S. J., Liden, R. C., Kraimer, M. L., \& Graf, I. K. (1999). The role of human capital, motivation and supervisor sponsorship in predicting career success. Journal of Organizational Behavior, 20, 577-595. doi:10.1002/(SICI)10991379(199909)20:5<577::AID-JOB958>3.0.CO;2-0

Weick, K. (1996). Enactment and the boundaryless career: Organizing as we work. In M. B. Arthur \& D. M. Rousseau (Eds.), The boundaryless career: A new employment principle for a new organizational era (pp. 40-57). Oxford, UK: Oxford University Press.

Wilhelm, F., \& Hirschi, A. (2019). Career self-management as a key factor for career wellbeing. In I.L. Potgieter, N. Ferreira \& M. Coetzee (Eds.), Theory, research and dynamics of career wellbeing (pp. 117-138). Basel, Switzerland: Springer.

Williams, T., \& Williams, K. (2010). Self-efficacy and performance in mathematics: Reciprocal determinism in 33 nations. Journal of Educational Psychology, 102, 453466. doi:10.1037/a0017271

Wolf, B. M., Herrmann, M., \& Brandstätter, V. (2018). Self-efficacy vs. action orientation: Comparing and contrasting two determinants of goal setting and goal striving. Journal of Research in Personality, 73, 35-45. doi:10.1016/j.jrp.2017.11.001

Wood, R., \& Bandura, A. (1989). Social cognitive theory of organizational management. Academy of Management Review, 14, 361-384. doi:10.5465/amr.1989.4279067 
Yeo, G. B., \& Neal, A. (2006). An examination of the dynamic relationship between selfefficacy and performance across levels of analysis and levels of specificity. Journal of Applied Psychology, 91, 1088-1101. doi:10.1037/0021-9010.91.5.1088 


\section{Funding:}

This research was made possible by a grant to the second author from the Federal Ministry of

Education and Research (BMBF, Grant-Nr.: 16FWN009). We gratefully acknowledge this support. 
Table 1

Descriptive statistics, internal consistencies, and correlations among study variables

\begin{tabular}{|c|c|c|c|c|c|c|c|c|c|c|c|c|c|c|c|c|c|}
\hline & Variable & 1 & 2 & 3 & 4 & 5 & 6 & 7 & 8 & 9 & 10 & 11 & 12 & 13 & 14 & 15 & 16 \\
\hline 1 & Career insecurity $\mathrm{T} 1$ & .65 & & & & & & & & & & & & & & & \\
\hline 2 & Career insecurity $\mathrm{T} 2$ & $.73 *$ & .68 & & & & & & & & & & & & & & \\
\hline 3 & Career insecurity $\mathrm{T} 3$ & $.67 *$ & $.74 *$ & .68 & & & & & & & & & & & & & \\
\hline 4 & Career insecurity $\mathrm{T} 4$ & $.58^{*}$ & $.67^{*}$ & $.73^{*}$ & .69 & & & & & & & & & & & & \\
\hline 5 & Career insecurity $\mathrm{T} 5$ & $.51 *$ & $.56^{*}$ & $.64^{*}$ & $.68^{*}$ & .71 & & & & & & & & & & & \\
\hline 6 & Career insecurity $\mathrm{T} 6$ & $.48^{*}$ & $.53 *$ & $.57^{*}$ & $.62 *$ & $.74 *$ & .73 & & & & & & & & & & \\
\hline 7 & Career insecurity $\mathrm{T} 7$ & $.42 *$ & $.47^{*}$ & $.51^{*}$ & $.57 *$ & $.67^{*}$ & $.74 *$ & .74 & & & & & & & & & \\
\hline 8 & Career insecurity $\mathrm{T} 8$ & $.46^{*}$ & $.47^{*}$ & $.53 *$ & $.58 *$ & $.62 *$ & $.70 *$ & $.74 *$ & .74 & & & & & & & & \\
\hline 9 & Self-management T1 & $-.24 *$ & $-.23 *$ & $-.20 *$ & $-.17 *$ & $-.18 *$ & $-.16^{*}$ & $-.15^{*}$ & $-.13^{*}$ & .75 & & & & & & & \\
\hline 10 & Self-management T2 & $-.27 *$ & $-.27 *$ & $-.24^{*}$ & $-.21 *$ & $-.20^{*}$ & $-.17 *$ & $-.21 *$ & $-.20^{*}$ & $.46^{*}$ & .75 & & & & & & \\
\hline 11 & Self-management T3 & $-.26^{*}$ & $-.26^{*}$ & $-.33^{*}$ & $-.28^{*}$ & $-.24 *$ & $-.24 *$ & $-.24 *$ & $-.19^{*}$ & $.40^{*}$ & $.50^{*}$ & .75 & & & & & \\
\hline 12 & Self-management T4 & $-.15^{*}$ & $-.16^{*}$ & $-.19 *$ & $-.29 *$ & $-.26^{*}$ & $-.20^{*}$ & $-.18^{*}$ & $-.19^{*}$ & $.33^{*}$ & $.41^{*}$ & $.43^{*}$ & .77 & & & & \\
\hline 13 & Self-management T5 & $-.16^{*}$ & $-.15^{*}$ & $-.17 *$ & $-.17 *$ & $-.27 *$ & $-.24 *$ & $-.23 *$ & $-.21^{*}$ & $.35^{*}$ & $.37 *$ & $.38^{*}$ & $.44 *$ & .76 & & & \\
\hline 14 & Self-management T6 & $-.16^{*}$ & $-.14 *$ & $-.16^{*}$ & $-.18^{*}$ & $-.21^{*}$ & $-.29 *$ & $-.21 *$ & $-.23^{*}$ & $.33^{*}$ & $.33^{*}$ & $.40^{*}$ & $.43 *$ & $.52 *$ & .78 & & \\
\hline 15 & Self-management T7 & $-.16^{*}$ & $-.14^{*}$ & $-.16^{*}$ & $-.16^{*}$ & $-.18^{*}$ & $-.22 *$ & $-.29 *$ & $-.24^{*}$ & $.28^{*}$ & $.32 *$ & $.37^{*}$ & $.35^{*}$ & $.46^{*}$ & $.50 *$ & .75 & \\
\hline 16 & Self-management T8 & $-.18^{*}$ & $-.17 *$ & $-.18^{*}$ & $-.22 *$ & $-.20^{*}$ & $-.19^{*}$ & $-.23 *$ & $-.32 *$ & $.29^{*}$ & $.35^{*}$ & $.36^{*}$ & $.40^{*}$ & $.36^{*}$ & $.44^{*}$ & $.50^{*}$ & .74 \\
\hline 17 & Self-efficacy T1 & $-.47^{*}$ & $-.42 *$ & $-.43^{*}$ & $-.38^{*}$ & $-.33^{*}$ & $-.31 *$ & $-.29 *$ & $-.31 *$ & $.30 *$ & $.22 *$ & $.22 *$ & $.18^{*}$ & $.14 *$ & $.13 *$ & $.14 *$ & $.18^{*}$ \\
\hline 18 & Self-efficacy T2 & $-.43^{*}$ & $-.49 *$ & $-.46^{*}$ & $-.42 *$ & $-.36^{*}$ & $-.33^{*}$ & $-.29 *$ & $-.29^{*}$ & $.29^{*}$ & $.30^{*}$ & $.28^{*}$ & $.21^{*}$ & $.18^{*}$ & $.17^{*}$ & $.18^{*}$ & $.20^{*}$ \\
\hline 19 & Self-efficacy T3 & $-.44 *$ & $-.48^{*}$ & $-.50^{*}$ & $-.45^{*}$ & $-.37^{*}$ & $-.33^{*}$ & $-.32 *$ & $-.31 *$ & $.30^{*}$ & $.28^{*}$ & $.35^{*}$ & $.23^{*}$ & $.19^{*}$ & $.18^{*}$ & $.18^{*}$ & $.18^{*}$ \\
\hline 20 & Self-efficacy T4 & $-.40^{*}$ & $-.43 *$ & $-.45^{*}$ & $-.51^{*}$ & $-.41 *$ & $-.40 *$ & $-.35^{*}$ & $-.35^{*}$ & $.28 *$ & $.26^{*}$ & $.31^{*}$ & $.30^{*}$ & $.20^{*}$ & $.19 *$ & $.21^{*}$ & $.22 *$ \\
\hline 21 & Self-efficacy T5 & $-.36^{*}$ & $-.38^{*}$ & $-.42 *$ & $-.44^{*}$ & $-.46^{*}$ & $-.43 *$ & $-.36^{*}$ & $-.37^{*}$ & $.23 *$ & $.21^{*}$ & $.28^{*}$ & $.25^{*}$ & $.30^{*}$ & $.23 *$ & $.21 *$ & $.19^{*}$ \\
\hline 22 & Self-efficacy T6 & $-.37 *$ & -.40 & $-.45^{*}$ & $-.46^{*}$ & $-.45^{*}$ & $-.48^{*}$ & $-.41^{*}$ & $-.41^{*}$ & $.26^{*}$ & $.24 *$ & $.24^{*}$ & $.26^{*}$ & $.25^{*}$ & $.32 *$ & $.25^{*}$ & $.27 *$ \\
\hline 23 & Self-efficacy T7 & $-.34^{*}$ & $-.37 *$ & $-.40^{*}$ & $-.40^{*}$ & $-.43 *$ & $-.44^{*}$ & $-.48^{*}$ & $-.42 *$ & $.24^{*}$ & $.22 *$ & $.28^{*}$ & $.23^{*}$ & $.29 *$ & $.31^{*}$ & $.36^{*}$ & $.31 *$ \\
\hline \multirow[t]{3}{*}{24} & Self-efficacy T8 & $-.37 *$ & $-.39 *$ & $-.44^{*}$ & $-.43^{*}$ & $-.43 *$ & $-.43^{*}$ & $-.45^{*}$ & $-.48^{*}$ & $.23^{*}$ & $.22 *$ & $.22 *$ & $.22 *$ & $.22 *$ & $.25^{*}$ & $.29 *$ & $.35^{*}$ \\
\hline & $M$ & 3.82 & 3.78 & 3.78 & 3.77 & 3.69 & 3.68 & 3.57 & 3.51 & 3.56 & 3.61 & 3.59 & 3.70 & 3.76 & 3.77 & 3.79 & 3.78 \\
\hline & $S D$ & 1.13 & 1.15 & 1.16 & 1.14 & 1.20 & 1.20 & 1.20 & 1.20 & 1.03 & 1.03 & 1.01 & 1.04 & 1.02 & 1.03 & 0.99 & 0.96 \\
\hline
\end{tabular}

(table continues) 
Table 1 (continued)

\begin{tabular}{|c|c|c|c|c|c|c|c|c|c|}
\hline & Variable & 17 & 18 & 19 & 20 & 21 & 22 & 23 & 24 \\
\hline 17 & Self-efficacy T1 & .73 & & & & & & & \\
\hline 18 & Self-efficacy T2 & $.65^{*}$ & .81 & & & & & & \\
\hline 19 & Self-efficacy T3 & $.63^{*}$ & $.71 *$ & .83 & & & & & \\
\hline 20 & Self-efficacy T4 & $.59^{*}$ & $.66^{*}$ & $.69^{*}$ & .84 & & & & \\
\hline 21 & Self-efficacy T5 & $.53^{*}$ & $.59 *$ & $.62 *$ & $.69^{*}$ & .84 & & & \\
\hline 22 & Self-efficacy T6 & $.54^{*}$ & $.59 *$ & $.61^{*}$ & $.66^{*}$ & $.70^{*}$ & .85 & & \\
\hline 23 & Self-efficacy T7 & $.51 *$ & $.55^{*}$ & $.59^{*}$ & $.64 *$ & $.66^{*}$ & $.71^{*}$ & .86 & \\
\hline \multirow[t]{3}{*}{24} & Self-efficacy T8 & $.50^{*}$ & $.53 *$ & $.59 *$ & $.61 *$ & $.60^{*}$ & $.66^{*}$ & $.71^{*}$ & .87 \\
\hline & $M$ & 4.27 & 4.29 & 4.32 & 4.34 & 4.50 & 4.56 & 4.63 & 4.64 \\
\hline & $S D$ & 0.95 & 0.97 & 0.99 & 0.98 & 0.98 & 0.97 & 0.96 & 0.99 \\
\hline
\end{tabular}

Note. $N T 1=3,118 ; N T 2=2,531 ; N T 3=2,002 ; N T 4=1,406 ; N T 5=1,776, N T 6=1,520, N T 7=1,364, N T 8=1,267 ;$ Cronbach's $\alpha$ displayed in diagonal.

$* p<.001$. 
Table 2

Correlations among study variables

\begin{tabular}{|c|c|c|c|c|c|}
\hline & Variable & $\begin{array}{l}\text { Gender } \\
(1=\text { Male })\end{array}$ & $\begin{array}{l}\text { PhD status } \\
(1=\text { PhD holder })\end{array}$ & $\begin{array}{l}\text { Position } \\
(1=\text { Permanent })\end{array}$ & $\begin{array}{l}\text { Occupational field } \\
(1=\text { Academia })\end{array}$ \\
\hline 1 & Career insecurity $\mathrm{T} 1$ & $.20 * * *$ & $-.09 * * *$ & $.16^{* *}$ & $-.11 * * *$ \\
\hline 2 & Career insecurity $\mathrm{T} 2$ & $.21 * * *$ & $-.05^{*}$ & $.20 * *$ & $-.13 * * *$ \\
\hline 3 & Career insecurity $\mathrm{T} 3$ & $.21 * * *$ & -.03 & $.24 * *$ & $-.16^{* * *}$ \\
\hline 4 & Career insecurity T4 & $.19 * * *$ & .02 & $.27^{* *}$ & $-.13 * * *$ \\
\hline 5 & Career insecurity $\mathrm{T} 5$ & $.19 * * *$ & .01 & $.41^{* *}$ & $-.25 * * *$ \\
\hline 6 & Career insecurity T6 & $.18 * * *$ & .04 & $.43^{* *}$ & $-.27 * * *$ \\
\hline 7 & Career insecurity $\mathrm{T} 7$ & $.20 * * *$ & $.07 *$ & $.47 * *$ & $-.29 * * *$ \\
\hline 8 & Career insecurity $\mathrm{T} 8$ & $.18 * * *$ & .03 & $.49^{* *}$ & $-.27 * * *$ \\
\hline 9 & Self-management T1 & .03 & $-.13 * * *$ & $-.09 * * *$ & $.07 * * *$ \\
\hline 10 & Self-management T2 & $.06^{* *}$ & $-.13 * * *$ & $-.10 * * *$ & $.07 * * *$ \\
\hline 11 & Self-management T3 & .03 & $-.14 * *$ & $-.17 * * *$ & $.15^{* * *}$ \\
\hline 12 & Self-management T4 & .04 & $-.13 * * *$ & $-.19 * * *$ & $.12 * * *$ \\
\hline 13 & Self-management T5 & .02 & $-.13 * * *$ & $-.17 * * *$ & $.17 * * *$ \\
\hline 14 & Self-management T6 & .05 & $-.10 * * *$ & $-.15 * * *$ & $.17 * * *$ \\
\hline 15 & Self-management T7 & .03 & $-.10 * * *$ & $-.15 * * *$ & $.17 * * *$ \\
\hline 16 & Self-management T8 & .00 & $-.06^{*}$ & $-.21 * * *$ & $.16^{* * *}$ \\
\hline 17 & Self-efficacy T1 & $-.20 * * *$ & $-.04 *$ & $-.09 * * *$ & $.05^{* *}$ \\
\hline 18 & Self-efficacy T2 & $-.21 * * *$ & $-.08 * * *$ & $-.14 * * *$ & $.09 * * *$ \\
\hline 19 & Self-efficacy T3 & $-.22 * * *$ & $-.10 * * *$ & $-.15 * * *$ & $.10^{* * *}$ \\
\hline 20 & Self-efficacy T4 & $-.20 * * *$ & $-.09 * * *$ & $-.14 * * *$ & $.09 * * *$ \\
\hline 21 & Self-efficacy T5 & $-.23 * * *$ & $-.08 * * *$ & $-.19 * * *$ & $.12 * * *$ \\
\hline 22 & Self-efficacy T6 & $-.19 * * *$ & $-.12 * * *$ & $-.19 * * *$ & $.10^{* * *}$ \\
\hline 23 & Self-efficacy T7 & $-.21 * * *$ & $-.10 * * *$ & $-.20 * * *$ & $.11 * * *$ \\
\hline 24 & Self-efficacy T8 & $-.17 * * *$ & $-.07 * *$ & $-.23 * * *$ & $12 * * *$ \\
\hline
\end{tabular}

Note. $N T 1=3,118 ; N T 2=2,531 ; N T 3=2,002 ; N T 4=1,406 ; N T 5=1,776, N T 6=1,520, N T 7=1,364, N T 8=1,267$;

$* * * p<.001, * * p<.01, * p<.05$. 
Table 3

Measurement invariance models

\begin{tabular}{|c|c|c|c|c|c|c|c|c|}
\hline & Model & $\chi^{2}$ & $d f$ & TLI & CFI & RSMEA $(90 \% \mathrm{CI})$ & SMSR & $\Delta \mathrm{CFI}$ \\
\hline \multirow{2}{*}{$\begin{array}{l}\text { Self- } \\
\text { management }\end{array}$} & Configural invariance & $198.35^{*}$ & 140 & .993 & .996 & $.012(.008-.015)$ & .019 & \\
\hline & Strong invariance & $241.96^{*}$ & 160 & .991 & .995 & $.013(.010-.016)$ & .022 & -.001 \\
\hline \multirow{2}{*}{$\begin{array}{l}\text { Self- } \\
\text { efficacy }\end{array}$} & Configural invariance & $614.92 *$ & 154 & .984 & .971 & $.031(.028-.034)$ & .024 & \\
\hline & Strong invariance & $741.85^{*}$ & 174 & .980 & .968 & $.032(.030-.035)$ & .033 & -.003 \\
\hline \multirow{2}{*}{$\begin{array}{l}\text { Career } \\
\text { insecurity }\end{array}$} & Configural invariance & $380.98 *$ & 140 & .981 & .990 & $.023(.021-.026)$ & .035 & \\
\hline & Strong invariance & $491.81 *$ & 160 & .977 & .986 & $.026(.023-.028)$ & .037 & -.004 \\
\hline
\end{tabular}

Note. TLI =Tucker-Lewis index; CFI = comparative fit index; RMSEA = root-mean-square error of approximation; CI = confidence interval; SMSR = Standardized Root Mean Squared Residual; $\Delta$ symbolizes different scores between models.

$* p<.001$. 
Table 4

Fit indices and model comparisons for nested models

\begin{tabular}{|c|c|c|c|c|c|c|c|c|c|}
\hline Variable & $\chi^{2}$ & $d f$ & TLI & CFI & RSMEA $(90 \% \mathrm{CI})$ & SMSR & $\mathrm{CM}$ & $\Delta \mathrm{CFI}$ & $\Delta \chi 2(d f)^{\mathrm{a}}$ \\
\hline M0 Stability model & $636.73 *$ & 225 & .976 & .980 & $.024(.022-.026)$ & .039 & M4 & .006 & $169.98(42)^{*}$ \\
\hline $\mathrm{M} 1 \mathrm{M} 0+\mathrm{SM} \leftarrow \rightarrow \mathrm{SE}$ & $583.78 *$ & 211 & .976 & .982 & $.024(.021-.026)$ & .037 & M4 & .004 & $118.56(26)^{*}$ \\
\hline $\mathrm{M} 2 \mathrm{M} 1+\mathrm{SM} \rightarrow \mathrm{CIn}+\mathrm{SE} \rightarrow \mathrm{CIn}$ & $548.26^{*}$ & 197 & .976 & .983 & $.024(.021-.026)$ & .037 & M4 & .003 & $83.40(14)^{*}$ \\
\hline $\mathrm{M} 3 \mathrm{M} 1+\mathrm{CIn} \rightarrow \mathrm{SM}+\mathrm{CIn} \rightarrow \mathrm{SE}$ & $507.00 *$ & 197 & .979 & .985 & $.022(.020-.025)$ & .035 & M4 & .001 & $42.63(14)^{*}$ \\
\hline $\begin{array}{l}\text { M4 RI-CLPM (full reciprocal model, M2 + M3) with } \\
\text { free structural coefficients }\end{array}$ & $464.29 *$ & 183 & .979 & .986 & $.022(.020-.025)$ & .033 & M4 & & \\
\hline M5 RI-CLPM without random intercept for SM & $1053.93^{*}$ & 186 & .938 & .958 & $.039(.036-.041)$ & .089 & M4 & .028 & $414.88(3)^{*}$ \\
\hline \multicolumn{10}{|l|}{ M6 M4 + auto-regressive paths constrained } \\
\hline M6a M4 + SE paths constrained & $471.13 *$ & 189 & .980 & .986 & $.022(.019-.024)$ & .033 & M4 & .000 & 6.43 (6) n.s. \\
\hline M6b M6a + SM paths constrained & $482.17 *$ & 195 & .980 & .986 & $.022(.019-.024)$ & .033 & M6a & .000 & 12.07 (6) n.s. \\
\hline M6c M6b + CIn paths constrained & $524.89 *$ & 201 & .978 & .984 & $.023(.020-.025)$ & .032 & M6b & .002 & $40.76(6)^{*}$ \\
\hline \multicolumn{10}{|l|}{ M7 M6b + cross-lagged paths constrained } \\
\hline M7a M6b + SE $\rightarrow$ SM path constrained & $487.50 *$ & 201 & .981 & .986 & $.021(.019-.024)$ & .033 & M6b & .000 & 5.04 (6) n.s. \\
\hline $\mathrm{M} 7 \mathrm{~b} \mathrm{M} 7 \mathrm{a}+\mathrm{SE} \rightarrow \mathrm{CIn}$ path constrained & $494.53 *$ & 207 & .981 & .986 & $.021(.019-.023)$ & .033 & $78 \mathrm{a}$ & .000 & $5.43(6)$ n.s. \\
\hline $\mathrm{M} 7 \mathrm{c} \mathrm{M} 7 \mathrm{~b}+\mathrm{SM} \rightarrow \mathrm{SE}$ path constrained & $505.16^{*}$ & 213 & .982 & .986 & $.021(.019-.023)$ & .033 & M7b & .000 & $10.25(6)$ n.s. \\
\hline $\mathrm{M} 7 \mathrm{~d}$ M7c $+\mathrm{SM} \rightarrow$ CIn path constrained & $515.42 *$ & 219 & .982 & .986 & $.021(.018-.023)$ & .033 & M7c & .000 & $11.70(6)$ n.s. \\
\hline M7e M7d + CIn $\rightarrow$ SM path constrained & $525.86^{*}$ & 225 & .982 & .985 & $.021(.018-.023)$ & .034 & M7d & .001 & $7.74(6)$ n.s. \\
\hline $\mathrm{M} 7 \mathrm{f} \mathrm{M} 7 \mathrm{e}+\mathrm{CIn} \rightarrow \mathrm{SE}$ path constrained & $534.38 *$ & 231 & .982 & .985 & $.020(.018-.023)$ & .034 & M7e & .000 & 8.35 (6) n.s. \\
\hline $\begin{array}{l}\text { Final model: Reciprocal model with constrained auto- } \\
\text { regressive SM and SE paths, unconstrained auto- } \\
\text { regressive CIn paths, and all cross-lagged paths } \\
\text { constrained }\end{array}$ & $534.38^{*}$ & 231 & .982 & .985 & $.020(.018-.023)$ & .034 & & & \\
\hline
\end{tabular}

Note. $\mathrm{SM}=$ self-management; $\mathrm{SE}=$ self-efficacy; $\mathrm{CIn}=$ career insecurity; TLI = Tucker-Lewis index; CFI = comparative fit index; RMSEA = root-mean-square error of approximation; $\mathrm{CI}=$ confidence interval; SMSR $=$ Standardized Root Mean Squared Residual; CM = compared model; $\Delta$ symbolizes different scores between models. ${ }^{\mathrm{a} C h i}$ square difference calculated using the Satorra-Bentler Chi-square difference test.

$* p<.001$. 
Table 5

RI-CLPM (final model) estimates, control variables (gender, PhD status, position, occupational field) included

\begin{tabular}{|c|c|c|c|}
\hline Parameters & B & $\mathrm{SE}$ & $p$ \\
\hline \multicolumn{4}{|l|}{ Cross-lagged effects } \\
\hline $\mathrm{T} 1 \mathrm{SM} \rightarrow \mathrm{T} 2 \mathrm{CI}$ & -.05 & .01 & $<.001$ \\
\hline $\mathrm{T} 2 \mathrm{SM} \rightarrow \mathrm{T} 3 \mathrm{CI}$ & -.05 & .01 & $<.001$ \\
\hline $\mathrm{T} 3 \mathrm{SM} \rightarrow \mathrm{T} 4 \mathrm{CI}$ & -.05 & .01 & $<.001$ \\
\hline $\mathrm{T} 4 \mathrm{SM} \rightarrow \mathrm{T} 5 \mathrm{CI}$ & -.05 & .01 & $<.001$ \\
\hline $\mathrm{T} 5 \mathrm{SM} \rightarrow \mathrm{T} 6 \mathrm{CI}$ & -.05 & .01 & $<.001$ \\
\hline $\mathrm{T} 6 \mathrm{SM} \rightarrow \mathrm{T} 7 \mathrm{CI}$ & -.04 & .01 & $<.001$ \\
\hline $\mathrm{T} 7 \mathrm{SM} \rightarrow \mathrm{T} 8 \mathrm{CI}$ & -.04 & .01 & $<.001$ \\
\hline $\mathrm{T} 1 \mathrm{CI} \rightarrow \mathrm{T} 2 \mathrm{SM}$ & -.04 & .01 & .011 \\
\hline $\mathrm{T} 2 \mathrm{CI} \rightarrow \mathrm{T} 3 \mathrm{SM}$ & -.04 & .02 & .012 \\
\hline $\mathrm{T} 3 \mathrm{CI} \rightarrow \mathrm{T} 4 \mathrm{SM}$ & -.03 & .01 & .012 \\
\hline $\mathrm{T} 4 \mathrm{CI} \rightarrow \mathrm{T} 5 \mathrm{SM}$ & -.03 & .01 & .012 \\
\hline $\mathrm{T} 5 \mathrm{CI} \rightarrow \mathrm{T} 6 \mathrm{SM}$ & -.04 & .02 & .012 \\
\hline $\mathrm{T} 6 \mathrm{CI} \rightarrow \mathrm{T} 7 \mathrm{SM}$ & -.04 & .02 & .012 \\
\hline $\mathrm{T} 7 \mathrm{CI} \rightarrow \mathrm{T} 8 \mathrm{SM}$ & -.04 & .01 & .012 \\
\hline $\mathrm{T} 1 \mathrm{SE} \rightarrow \mathrm{T} 2 \mathrm{CI}$ & -.05 & .01 & $<.001$ \\
\hline $\mathrm{T} 2 \mathrm{SE} \rightarrow \mathrm{T} 3 \mathrm{CI}$ & -.05 & .01 & $<.001$ \\
\hline $\mathrm{T} 3 \mathrm{SE} \rightarrow \mathrm{T} 4 \mathrm{CI}$ & -.05 & .01 & $<.001$ \\
\hline $\mathrm{T} 4 \mathrm{SE} \rightarrow \mathrm{T} 5 \mathrm{CI}$ & -.05 & .01 & $<.001$ \\
\hline $\mathrm{T} 5 \mathrm{SE} \rightarrow \mathrm{T} 6 \mathrm{CI}$ & -.04 & .01 & $<.001$ \\
\hline $\mathrm{T} 6 \mathrm{SE} \rightarrow \mathrm{T} 7 \mathrm{CI}$ & -.05 & .01 & $<.001$ \\
\hline $\mathrm{T} 7 \mathrm{SE} \rightarrow \mathrm{T} 8 \mathrm{CI}$ & -.03 & .01 & $<.001$ \\
\hline $\mathrm{T} 1 \mathrm{CI} \rightarrow \mathrm{T} 2 \mathrm{SE}$ & -.12 & .02 & $<.001$ \\
\hline $\mathrm{T} 2 \mathrm{CI} \rightarrow \mathrm{T} 3 \mathrm{SE}$ & -.12 & .02 & $<.001$ \\
\hline $\mathrm{T} 3 \mathrm{CI} \rightarrow \mathrm{T} 4 \mathrm{SE}$ & -.11 & .01 & $<.001$ \\
\hline $\mathrm{T} 4 \mathrm{CI} \rightarrow \mathrm{T} 5 \mathrm{SE}$ & -.11 & .01 & $<.001$ \\
\hline $\mathrm{T} 5 \mathrm{CI} \rightarrow \mathrm{T} 6 \mathrm{SE}$ & -.11 & .02 & $<.001$ \\
\hline $\mathrm{T} 6 \mathrm{CI} \rightarrow \mathrm{T} 7 \mathrm{SE}$ & -.12 & .02 & $<.001$ \\
\hline $\mathrm{T} 7 \mathrm{CI} \rightarrow \mathrm{T} 8 \mathrm{SE}$ & -.12 & .02 & $<.001$ \\
\hline $\mathrm{T} 1 \mathrm{SE} \rightarrow \mathrm{T} 2 \mathrm{SM}$ & .03 & .02 & .031 \\
\hline $\mathrm{T} 2 \mathrm{SE} \rightarrow \mathrm{T} 3 \mathrm{SM}$ & .03 & .02 & .032 \\
\hline $\mathrm{T} 3 \mathrm{SE} \rightarrow \mathrm{T} 4 \mathrm{SM}$ & .03 & .01 & .032 \\
\hline $\mathrm{T} 4 \mathrm{SE} \rightarrow \mathrm{T} 5 \mathrm{SM}$ & .03 & .01 & .032 \\
\hline $\mathrm{T} 5 \mathrm{SE} \rightarrow \mathrm{T} 6 \mathrm{SM}$ & .03 & .02 & .031 \\
\hline $\mathrm{T} 6 \mathrm{SE} \rightarrow \mathrm{T} 7 \mathrm{SM}$ & .03 & .02 & .032 \\
\hline $\mathrm{T} 7 \mathrm{SE} \rightarrow \mathrm{T} 8 \mathrm{SM}$ & .03 & .02 & .032 \\
\hline $\mathrm{T} 1 \mathrm{SM} \rightarrow \mathrm{T} 2 \mathrm{SE}$ & .06 & .01 & $<.001$ \\
\hline $\mathrm{T} 2 \mathrm{SM} \rightarrow \mathrm{T} 3 \mathrm{SE}$ & .06 & .01 & $<.001$ \\
\hline $\mathrm{T} 3 \mathrm{SM} \rightarrow \mathrm{T} 4 \mathrm{SE}$ & .06 & .01 & $<.001$ \\
\hline
\end{tabular}

(table continues) 
Table 5 (continued)

\begin{tabular}{|c|c|c|c|}
\hline $\mathrm{T} 4 \mathrm{SM} \rightarrow \mathrm{T} 5 \mathrm{SE}$ & .06 & .01 & $<.001$ \\
\hline $\mathrm{T} 5 \mathrm{SM} \rightarrow \mathrm{T} 6 \mathrm{SE}$ & .06 & .01 & $<.001$ \\
\hline $\mathrm{T} 6 \mathrm{SM} \rightarrow \mathrm{T} 7 \mathrm{SE}$ & .06 & .01 & $<.001$ \\
\hline $\mathrm{T} 7 \mathrm{SM} \rightarrow \mathrm{T} 8 \mathrm{SE}$ & .06 & .01 & $<.001$ \\
\hline \multicolumn{4}{|l|}{ Stability paths } \\
\hline $\mathrm{T} 1 \mathrm{SM} \rightarrow \mathrm{T} 2 \mathrm{SM}$ & .18 & .02 & $<.001$ \\
\hline $\mathrm{T} 2 \mathrm{SM} \rightarrow \mathrm{T} 3 \mathrm{SM}$ & .19 & .02 & $<.001$ \\
\hline $\mathrm{T} 3 \mathrm{SM} \rightarrow \mathrm{T} 4 \mathrm{SM}$ & .17 & .02 & $<.001$ \\
\hline $\mathrm{T} 4 \mathrm{SM} \rightarrow \mathrm{T} 5 \mathrm{SM}$ & .19 & .02 & $<.001$ \\
\hline T5 SM $\rightarrow$ T6 SM & .18 & .01 & $<.001$ \\
\hline T6 SM $\rightarrow$ T7 SM & .18 & .02 & $<.001$ \\
\hline $\mathrm{T} 7 \mathrm{SM} \rightarrow \mathrm{T} 8 \mathrm{SM}$ & .18 & .02 & $<.001$ \\
\hline $\mathrm{T} 1 \mathrm{CI} \rightarrow \mathrm{T} 2 \mathrm{CI}$ & .46 & .03 & $<.001$ \\
\hline $\mathrm{T} 2 \mathrm{CI} \rightarrow \mathrm{T} 3 \mathrm{CI}$ & .42 & .03 & $<.001$ \\
\hline $\mathrm{T} 3 \mathrm{CI} \rightarrow \mathrm{T} 4 \mathrm{CI}$ & .36 & .04 & $<.001$ \\
\hline $\mathrm{T} 4 \mathrm{CI} \rightarrow \mathrm{T} 5 \mathrm{CI}$ & .25 & .05 & $<.001$ \\
\hline $\mathrm{T} 5 \mathrm{CI} \rightarrow \mathrm{T} 6 \mathrm{CI}$ & .37 & .04 & $<.001$ \\
\hline $\mathrm{T} 6 \mathrm{CI} \rightarrow \mathrm{T} 7 \mathrm{CI}$ & .42 & .03 & $<.001$ \\
\hline $\mathrm{T} 7 \mathrm{CI} \rightarrow \mathrm{T} 8 \mathrm{CI}$ & .35 & .03 & $<.001$ \\
\hline $\mathrm{T} 1 \mathrm{SE} \rightarrow \mathrm{T} 2 \mathrm{SE}$ & .21 & .02 & $<.001$ \\
\hline $\mathrm{T} 2 \mathrm{SE} \rightarrow \mathrm{T} 3 \mathrm{SE}$ & .21 & .02 & $<.001$ \\
\hline $\mathrm{T} 3 \mathrm{SE} \rightarrow \mathrm{T} 4 \mathrm{SE}$ & .20 & .02 & $<.001$ \\
\hline $\mathrm{T} 4 \mathrm{SE} \rightarrow \mathrm{T} 5 \mathrm{SE}$ & .20 & .02 & $<.001$ \\
\hline $\mathrm{T} 5 \mathrm{SE} \rightarrow \mathrm{T} 6 \mathrm{SE}$ & .21 & .02 & $<.001$ \\
\hline $\mathrm{T} 6 \mathrm{SE} \rightarrow \mathrm{T} 7 \mathrm{SE}$ & .21 & .02 & $<.001$ \\
\hline $\mathrm{T} 7 \mathrm{SE} \rightarrow \mathrm{T} 8 \mathrm{SE}$ & .19 & .02 & $<.001$ \\
\hline
\end{tabular}

Note. $\mathrm{SM}=$ self-management; $\mathrm{SE}=$ self-efficacy; $\mathrm{CI}=$ career insecurity. 


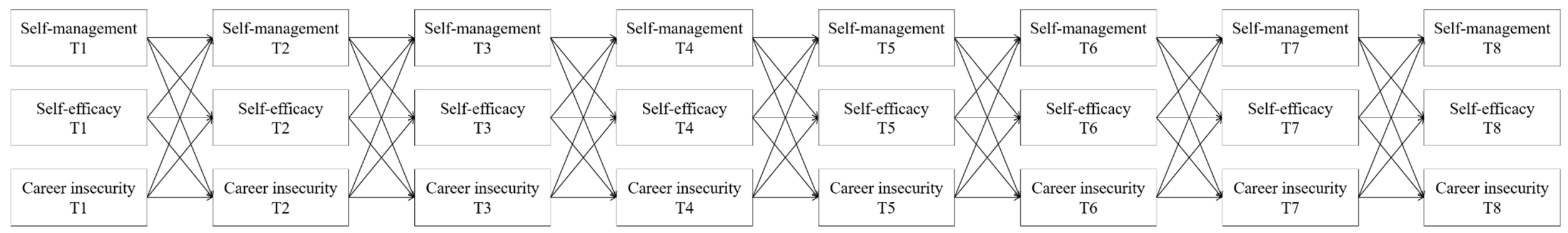

Fig.1. A depiction of theoretically expected relationships between self-management, self-efficacy, and career insecurity as hypothesized in the current study. 


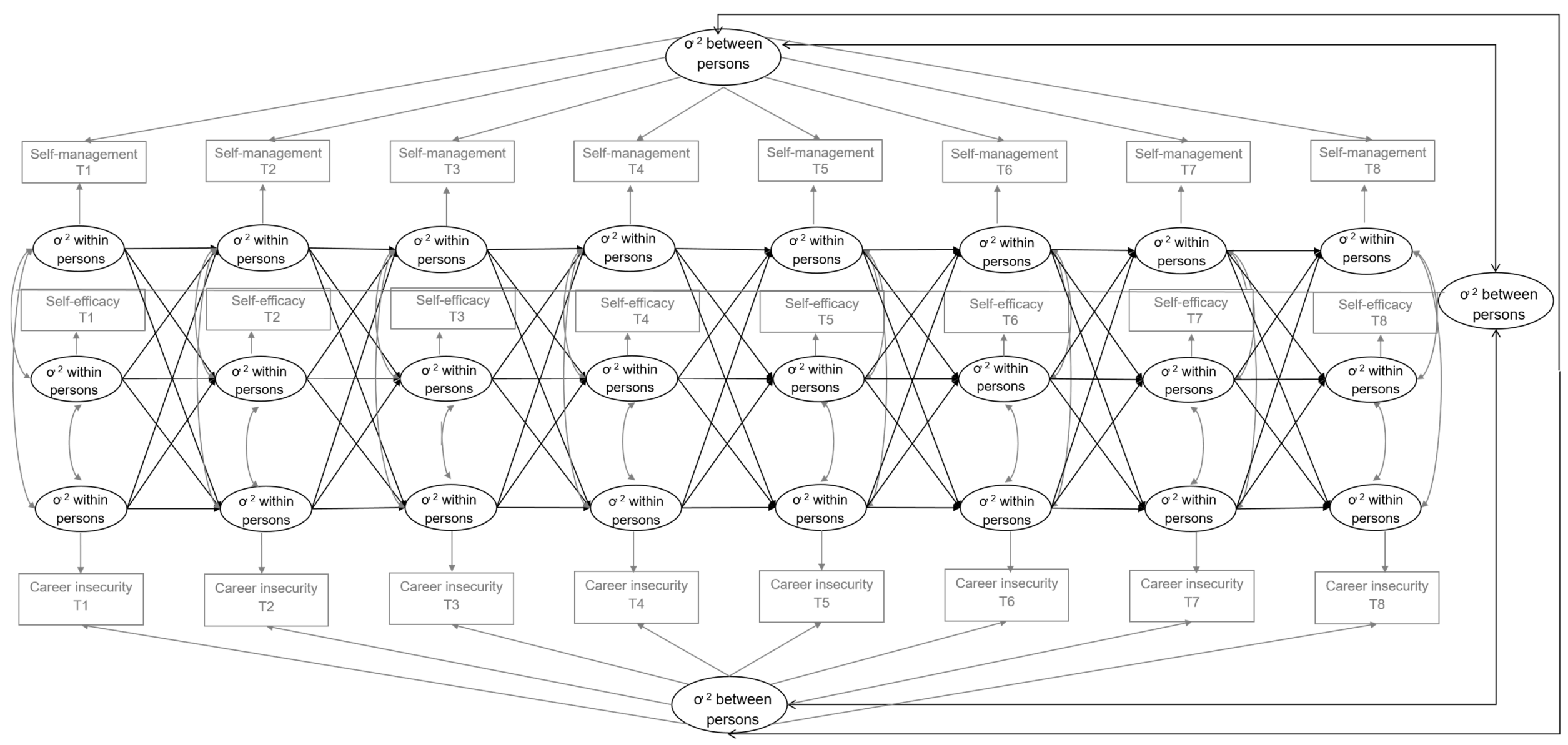

Fig.2. The random intercept cross-lagged panel model (RI-CLPM). The observed variables are represented in the squares. Latent variables are displayed as ovals. The three random intercepts represent the between-person variances. The latent within-person variables represent the withinperson variances. 


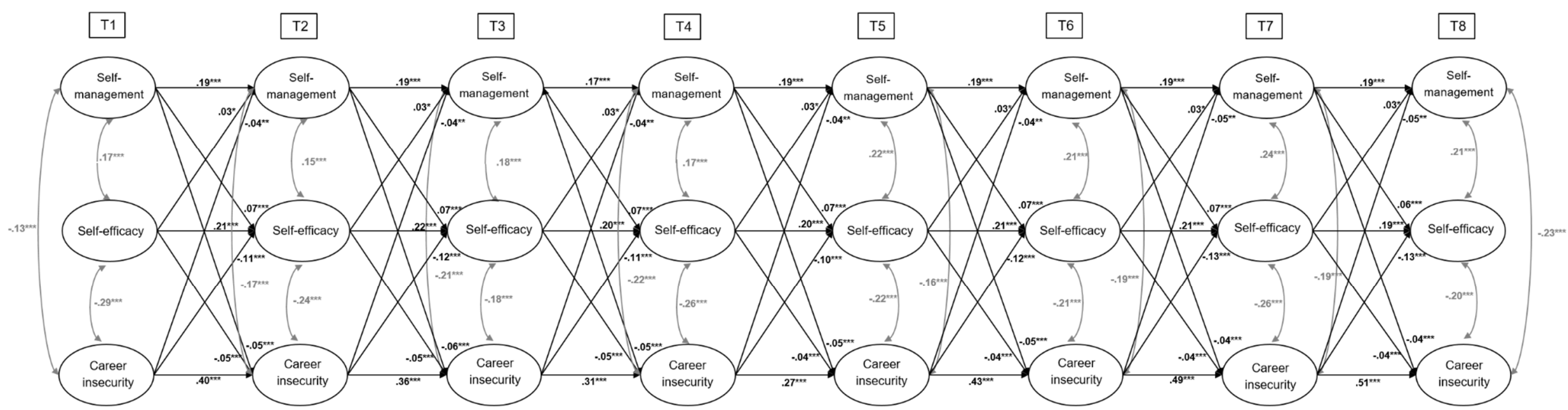

Fig.3 Significant paths for the within-person relationship between work-related self-management, occupational self-efficacy, and career insecurity in the final random-intercepts cross-lagged panel model (RI-CLPM, Model M7f). Ovals represent within-person factors. Coefficients represent standardized beta values. For clarity, the observed variables, between-person factors (see Fig. 2), and error terms are not shown.

$* * * p<.001, * * p<.01, * p<.05$. 